\title{
Theoretical Evaluation of the Vapor Compression Cycle With a Liquid-Line/ Suction-Line Heat Exchanger, Economizer, and Ejector
}

Piotr A. Domanski

March 1995

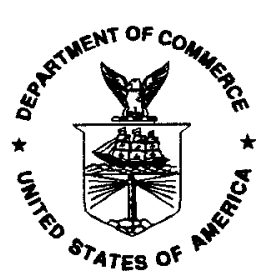

U.S. Department of Commerce

Ronald H. Brown, Secretary

Technology Administration

Mary L. Good, Under Secretary for Technology

National Institute of Standards and Technology

Arati Prabhakar, Director 


\begin{abstract}
The report presents a theoretical analysis of three vapor compression cycles which are derived from the Rankine cycle by incorporating a liquid-line/suction-line heat exchanger, economizer, or ejector. These addendums to the basic cycle reduce throttling losses using different principles, and they require different mechanical hardware of different complexity and cost. The theoretical merits of the three modified cycles were evaluated in relation to the reversed Carnot and Rankine cycle. Thirty-eight fluids were included in the study using the Carnahan-Starling-DeSantis equation of state. In general, the benefit of these addendums increases with the amount of the throttling losses realized by the refrigerant in the Rankine cycle. The liquid-line/suction-line heat exchange cycle shows the smallest COP improvement. Theoretically, the ejector cycle can reach the highest COP, but this requires a high level of ejector efficiency, which has not been demonstrated to be feasible in practice. If the two-phase ejector efficiency is assigned the value attainable in a typical single-phase ejector, the COP of the ejector cycle is comparable to the COP of the onestage economizer cycle.
\end{abstract}

Key Words: air conditioning; ejector; liquid-line/suction-line heat exchange; Rankine cycle; refrigeration; vapor compression cycle 


\section{ACKNOWLEDGEMENT}

This study was sponsored by the Advanced Technology Program at the National Institute of Standards and Technology. The author thanks Mr. P. Rothfleisch and Dr. D. Didion of NIST and Mr. P. Glamm of the Trane Company for their review and comments on the draft of this report. 


\section{TABLE OF CONTENTS}

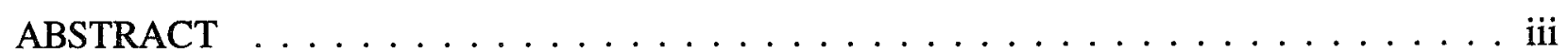

ACKNOWLEDGEMENT $\ldots \ldots \ldots \ldots \ldots \ldots \ldots \ldots \ldots \ldots \ldots$

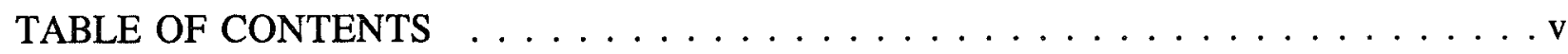

LIST OF FIGURES $\ldots \ldots \ldots \ldots \ldots \ldots \ldots \ldots \ldots \ldots \ldots$

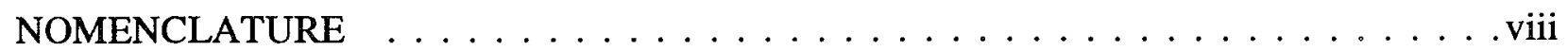

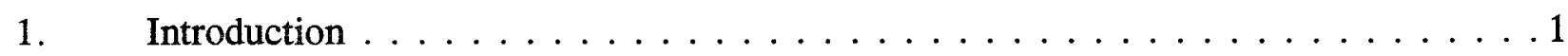

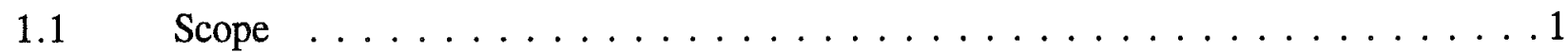

1.2 Theoretical Background $\ldots \ldots \ldots \ldots \ldots \ldots$

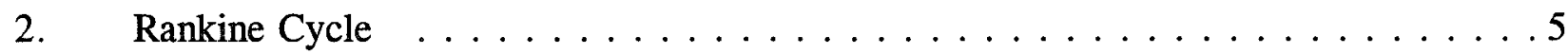

3. Cycle with a Liquid-Line/Suction-Line Heat Exchanger . . . . . . . . . . . 10

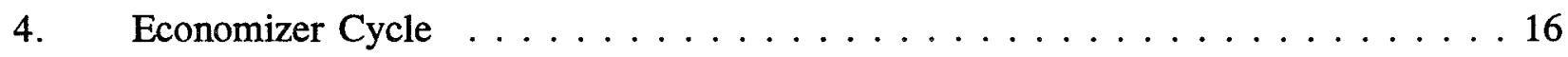

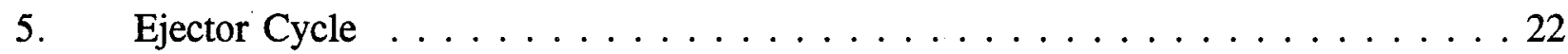

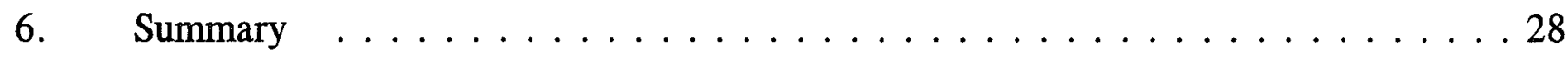

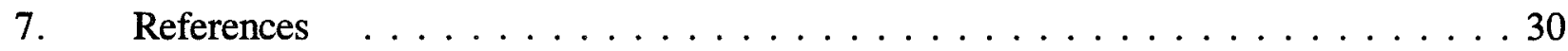




\section{LIST OF FIGURES}

1. Carnot and Rankine cycle . . . . . . . . . . . . . . . . . . 3

2. Reciprocal of the slope of saturated vapor line (ds/dT) on T-S

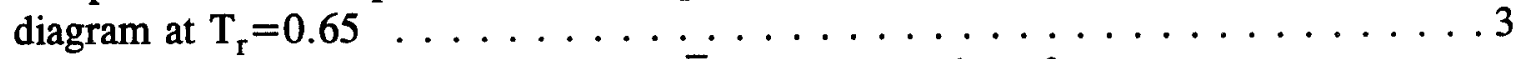

3. Values of $\mathrm{h}_{\mathrm{fg}} / \mathrm{T}_{\text {evap }}\left(\right.$ at $\left.\mathrm{T}_{\mathrm{r}}=0.65\right)$ and $\overline{\mathrm{c}}_{\mathrm{p}, \mathrm{l}}$ (average value of

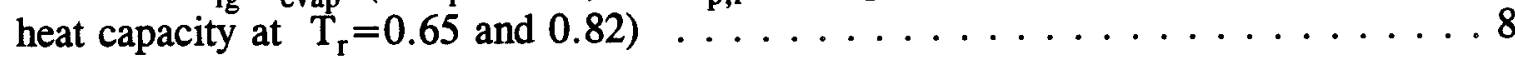

4. Relation between $\left(\mathrm{T}_{\text {evap }} \cdot \overline{\mathrm{c}}_{\mathrm{p}, \mathrm{l}}\right) / \mathrm{h}_{\mathrm{fg}}$ and molar heat capacity of

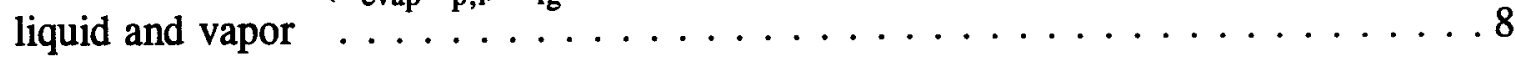

5. COP of the Rankine cycle and the cycle without throttling irreversibilities referenced to $\operatorname{COP}_{\mathrm{C}} \ldots \ldots \ldots \ldots \ldots \ldots$

6. Relative penalties degrading the Rankine cycle COP ...........

7. Schematic of hardware arrangements for the basic cycle and cycle with the liquid-line/suction-line heat exchanger $\ldots \ldots \ldots \ldots \ldots 11$

8. Key refrigerant state points in the basic cycle and llsl-hx cycle $\ldots \ldots \ldots \ldots 11$

9. Change of the $\mathrm{COP}_{\mathrm{hx}}$ at different effectiveness of the llsl-hx at

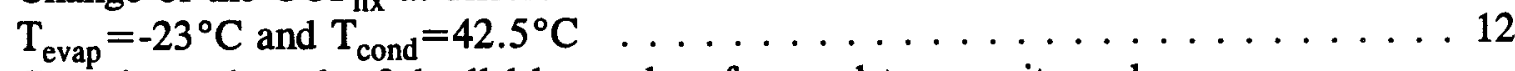

10. Capacity and work of the llsl-hx cycle referenced to capacity and

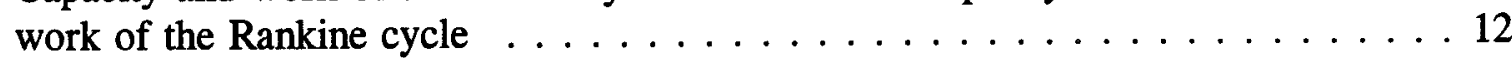

11. COP of the llsl-hx cycle referenced to $\mathrm{COP}_{\mathrm{C}}\left(\mathrm{T}_{\text {evap, } \mathrm{r}}=0.65\right.$, $\mathrm{T}_{\text {cond }, \mathrm{r}}=0.82$, refrigerants sorted by $\mathrm{c}_{\mathrm{p}, \mathrm{v}}$ at $\mathrm{T}_{\text {evap, } \mathrm{r}} \mathrm{r}, \ldots \ldots \ldots \ldots \ldots \ldots \ldots$

12. The effect of vapor-side pressure drop in the llsl-hx on the $\operatorname{COP}_{\mathrm{hx}}$ for R-123 and R-125 $\left(\mathrm{T}_{\mathrm{e}, \mathrm{r}}=0.65, \mathrm{~T}_{\mathrm{c}, \mathrm{r}}=0.82, \eta_{\mathrm{hx}}=0.5\right) \ldots \ldots \ldots 14$

13. $C O P$ of the llsl-hx cycle referenced to $\operatorname{COP}_{C}\left(T_{\text {evap }}=8^{\circ} \mathrm{C}, \mathrm{T}_{\text {cond }}=46^{\circ} \mathrm{C}\right.$,

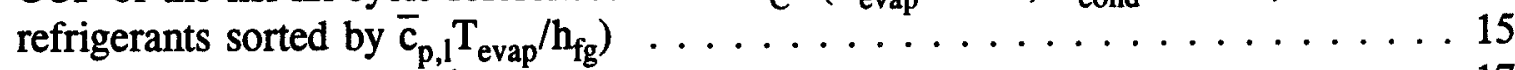

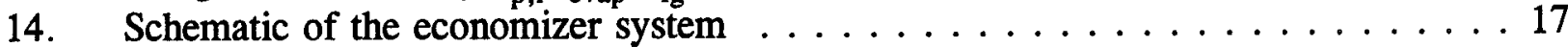

15. Pressure-enthalpy diagram with economizer cycle . . . . . . . . . . 17

16. Capacity and work for the economizer cycle referenced to capacity and work for the Rankine cycle $\left(\mathrm{T}_{\text {evap, } \mathrm{r}}=0.65, \mathrm{~T}_{\text {cond }, \mathrm{r}}=0.82\right) \ldots \ldots 19$

17. $\mathrm{COP}$ of the economizer cycle and Rankine cycle referenced to $\mathrm{COP}_{\mathrm{C}}$ $\left(\mathrm{T}_{\text {evap }, \mathrm{r}}=0.65, \mathrm{~T}_{\text {cond, } \mathrm{r}}=0.82\right.$, refrigerants sorted by $\mathrm{c}_{\mathrm{p}, \mathrm{v}}$ at $\left.\mathrm{T}_{\text {evap,r } \mathrm{r}}\right) \ldots \ldots 20$

18. Optimum intermediate temperature and pressure, and the geometric mean intermediate pressure $\left(\mathrm{T}_{\text {evap } \mathrm{r}}=0.65, \mathrm{~T}_{\text {cond }, \mathrm{r}}=0.82\right) \ldots \ldots 20$

19. $\mathrm{COP}_{\mathrm{ECO}}$ for R-12, R-227ea, R-717, and R-744 as a function of the intermediate temperature $\left(\mathrm{T}_{\text {evap }, \mathrm{r}}=0.65, \mathrm{~T}_{\text {cond }, \mathrm{r}}=0.82\right) \ldots \ldots 21$

20. COP of the economizer and Rankine cycle referenced to $\mathrm{COP}_{\mathrm{C}}$ $\left(\mathrm{T}_{\text {evap }}=8^{\circ} \mathrm{C}, \mathrm{T}_{\text {cond }}=46^{\circ} \mathrm{C}\right.$, refrigerants sorted by $\left.\overline{\mathrm{c}}_{\mathrm{p}, 1} \mathrm{~T}_{\text {evap }} / \mathrm{h}_{\mathrm{fg}}\right) \ldots \ldots 23$

21. Schematic of the ejector system and ejector . . . . . . . . . . . . 23

22. Capacity and work for the ejector cycle referenced to capacity and work for the Rankine cycle $\mathrm{T}_{\text {evap, } \mathrm{r}}=0.65, \mathrm{~T}_{\text {cond, } \mathrm{r}}=0.82$,

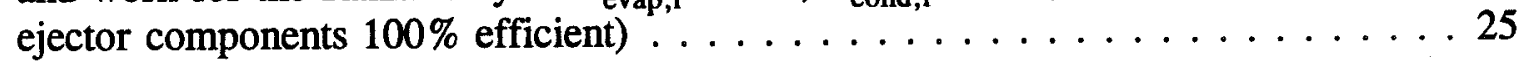

23. $\mathrm{COP}$ of the ejector cycle referenced to $\mathrm{COP}_{\mathrm{C}}\left(\mathrm{T}_{\text {evap }, \mathrm{r}}=0.65\right.$ and $\mathrm{T}_{\text {cond }, \mathrm{r}}=0.82$, refrigerants sorted by $\mathrm{c}_{\mathrm{p}, \mathrm{v}}$ at $\left.\mathrm{T}_{\text {evap, } \mathrm{r}}\right) \ldots \ldots \ldots \ldots \ldots \ldots \ldots$ 
24. COP improvement of the ejector cycle over the $\operatorname{COP}_{R} \quad\left(T_{\text {evap, },}=0.65\right.$ and $\mathrm{T}_{\text {cond }, \mathrm{r}}=0.82$, refrigerants sorted by $\mathrm{c}_{\mathrm{p}, \mathrm{v}}$ at $\left.\mathrm{T}_{\text {evap, } \mathrm{r}}\right) \ldots \ldots 26$

25. $\mathrm{COP}$ of the ejector cycle referenced to $\mathrm{COP}_{\mathrm{C}}\left(\mathrm{T}_{\text {evap }}=8^{\circ} \mathrm{C}, \mathrm{T}_{\text {cond }}=46^{\circ} \mathrm{C}\right.$,

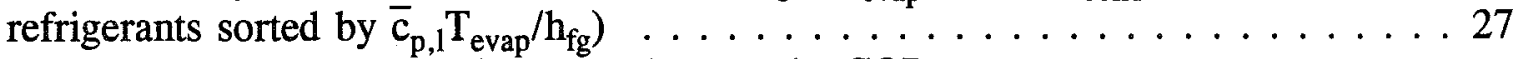

26. COP improvement of the ejector cycle over the $\mathrm{COP}_{R}$ $\left(\mathrm{T}_{\text {evap }}=8^{\circ} \mathrm{C}, \mathrm{T}_{\text {cond }}=46^{\circ} \mathrm{C}\right.$, refrigerants sorted by $\left.\bar{c}_{\mathrm{p}, 1} \mathrm{~T}_{\text {evap }} / \mathrm{h}_{\mathrm{fg}}\right) \ldots \ldots 27$

27. Improvement of volumetric capacity of the ejector cycle over that of the Rankine cycle $\left(\mathrm{T}_{\text {evap }}=8^{\circ} \mathrm{C}, \mathrm{T}_{\text {cond }}=46^{\circ} \mathrm{C}\right.$, refrigerants sorted by $\bar{c}_{\mathrm{p}, 1} \mathrm{~T}_{\mathrm{evap}} / \mathrm{h}_{\mathrm{fg}}$ ) 


\section{NOMENCLATURE}

COP - Coefficient of Performance

$c_{p}$ - molar heat capacity at constant pressure; $\bar{c}_{p}$ - average value

eff - efficiency of ejector components

$\mathrm{h}$ - enthalpy

$\mathrm{h}_{\mathrm{fg}}$ - latent heat of evaporation

llsl-hx - liquid-line/suction-line heat exchanger

$\mathrm{P}$ - pressure; $\mathrm{P}_{0.7^{-}}$saturation pressure at temperature equal to $0.7 \cdot \mathrm{T}_{\text {crit }}$

$\mathrm{R}$ - universal gas constant

s - entropy

$\mathrm{T}$ - temperature

u - velocity

$\mathrm{v}$ - specific volume

$\mathrm{Q}$ - heat, capacity

W - work

$\beta$ - coefficient of thermal expansion; $\bar{\beta}$ - average value

$\eta$ - nozzle efficiency

$\eta_{\mathrm{hx}}-$ effectiveness of llsl-hx

Subscripts:

C - Carnot

cond - condenser

crit - critical

d - diffuser, ejector

ECO - economizer

evap - evaporator

exp - related to isenthalpic expansion

$\mathrm{hx}$ - related to llsl-hx cycle

$\mathrm{i}$ - inlet

int - intermediate

$\mathrm{j}$ - ejector

1 - liquid

$\mathrm{m}$ - motive nozzle in ejector

o - outlet

R - Rankine

s - suction nozzle, ejector

sup - related to superheated vapor horn

$\mathrm{r}$ - reduced value

$\mathrm{v}$ - vapor

$\mathrm{x}$ - mixing, ejector 


\section{Introduction}

\subsection{Scope}

This study analyzes the performance of pure-component refrigerants in the basic refrigeration (reversed Rankine) cycle and in modified cycles in which the throttling-process irreversibilities are minimized. The three modified cycles considered here are:

- the liquid-line/suction-line heat exchange (llsl-hx) cycle

- the economizer cycle

- the ejector cycle.

Each of these cycles can achieve an improved Coefficient of Performance (COP) over that of the Rankine cycle by reducing throttling irreversibilities, but accomplishes this using different thermodynamic principles. COP improvements of these modified cycles are different and have to be realized at the expense of additional hardware of different complexity and cost. This study compares the potential of these cycles for a wide range of working fluids.

The refrigerants considered in this study were the 38 fluids covered by REFPROP [1], and REFPROP thermodynamic property routines were employed in simulation models used to evaluate their performance. The Carnahan-Starling-DeSantis equation of state was used for all fluids except ammonia, for which a high-accuracy formulation by Harr and Gallagher was applied. Table 1 lists the studied fluids and their basic thermodynamic properties.

\subsection{Theoretical Background}

Thermodynamically, all refrigerants have the same COP potential in the ideal vapor compression cycle. At prescribed condenser and evaporator temperatures, this potential is defined by the Coefficient of Performance of the reversed Carnot refrigeration cycle,

$$
\operatorname{COP}_{C}=\frac{T_{\text {evap }}}{T_{\text {cond }}-T_{\text {evap }}}
$$

The Carnot cycle consists of two isentropes and two isotherms. It is assumed to operate with infinite-area heat exchangers between two isothermal heat reservoirs. Since the Carnot cycle is completely reversible, it is an unattainable ideal model for a refrigeration cycle.

Consequently, the more realistic Rankine cycle is used to represent the thermodynamic processes in a refrigeration machine. The Rankine cycle is composed of two isobars, an adiabatic expansion and an isentropic compression. The Rankine cycle and Carnot cycle are shown in Figure 1. (Note that in the Carnot cycle presented Figure 1, lines $1-2_{\mathrm{C}}$ and $2 \mathrm{C}^{-2} \mathrm{~V}$ represent two compression processes, with process $2_{\mathrm{C}}-2_{\mathrm{V}}$ requiring an isothermal compressor). 
Table 1. Selected properties of studied refrigerants

\begin{tabular}{|c|c|c|c|c|c|c|c|c|}
\hline$\#$ & Refrigerant & $\begin{array}{l}\mathrm{T}_{\text {crit }} \\
{ }^{\circ} \mathrm{C}\end{array}$ & $\begin{array}{l}\mathrm{WM} \\
\mathrm{g} / \mathrm{mol}\end{array}$ & $\underset{\mathrm{kJ} / \mathrm{kmol}}{\mathrm{h}_{\mathrm{fg}}{ }^{*}}$ & $\underset{\mathrm{kJ} / \mathrm{kmol}_{\mathrm{pmol}}}{\mathrm{c}^{*}} \cdot \mathrm{K}$ & $\underset{\mathrm{kJ} / \mathrm{kmol} \cdot \mathrm{K}}{\mathrm{c}_{\mathrm{p}, 1}^{*}}$ & $\begin{array}{c}\mathrm{T}_{\mathrm{r}}=0.65 \\
{ }^{\circ} \mathrm{C}\end{array}$ & $\underset{\mathrm{r}}{\mathrm{T}_{\mathrm{r}}=0.82}$ \\
\hline 1 & R-14 & -45.6 & 88.0 & 11562.9 & 41.7 & 78.5 & -125.3 & -86.6 \\
\hline 2 & R-23 & 25.9 & 70.0 & 16857.1 & 42.3 & 89.2 & -78.7 & -28.0 \\
\hline 3 & R-13 & 28.9 & 104.5 & 15191.2 & 54.4 & 88.7 & -76.8 & -25.5 \\
\hline 4 & R-744 & 30.9 & 44.0 & 16445.9 & 34.0 & 78.3 & -75.5 & -23.9 \\
\hline 5 & $\mathrm{R}-125$ & 66.2 & 120 & 20001.1 & 80.5 & 132.2 & -52.6 & 5.1 \\
\hline 6 & R-13B1 & 67.1 & 148.9 & 17189.1 & 61.5 & 99.1 & -52.0 & 5.8 \\
\hline 7 & R-218 & 72.0 & 188.0 & 20431.6 & 125.1 & 170.5 & -48.8 & 9.9 \\
\hline 8 & $R-143 a$ & 73.1 & 84.0 & 19102.8 & 66.2 & 105.2 & -48.1 & 10.8 \\
\hline 9 & $R-32$ & 78.2 & 52.0 & 19829.2 & 39.5 & 78.5 & -44.8 & 15.0 \\
\hline 10 & $\mathrm{R}-115$ & 79.9 & 154.5 & 19575.9 & 93.9 & 138.4 & -43.7 & 16.4 \\
\hline 11 & R-22 & 96.2 & 86.5 & 19835.1 & 51.6 & 93.4 & -33.1 & 29.7 \\
\hline 12 & R-290 & 96.7 & 44.1 & 18330.5 & 65.3 & 102.7 & -32.8 & 30.1 \\
\hline 13 & R-134a & 101.1 & 102.0 & 22491.6 & 76.0 & 126.0 & -29.9 & 33.8 \\
\hline 14 & $\mathrm{R}-227 \mathrm{a}$ & 101.9 & 170.0 & 23256.6 & 120.6 & 179.0 & -29.4 & 34.4 \\
\hline 15 & $\mathrm{R}-245 \mathrm{cb}$ & 106.9 & 134.1 & 22508.3 & 107.1 & 159.4 & -26.1 & 38.5 \\
\hline 16 & $\mathrm{R}-12$ & 111.8 & 120.9 & 19684.3 & 68.2 & 107.4 & -22.9 & 42.5 \\
\hline 17 & R-152a & 113.6 & 66.0 & 21716.8 & 62.2 & 102.1 & -21.8 & 43.9 \\
\hline 18 & R-C318 & 115.2 & 200.0 & 24149.5 & 142.3 & 198.8 & -20.7 & 45.3 \\
\hline 19 & R-134 & 118.9 & 102.0 & 22746.2 & 83.9 & 131.5 & -18.3 & 48.4 \\
\hline 20 & R-124 & 122.5 & 136.5 & 22878.5 & 91.7 & 140.2 & -16.0 & 51.3 \\
\hline 21 & R-C270 & 125.2 & 42.1 & 19117.1 & 51.1 & 84.6 & $-14: 3$ & 53.5 \\
\hline 22 & NH3 & 132.2 & 17.0 & 21641.8 & 36.5 & 73.0 & -9.6 & 59.3 \\
\hline 23 & $R-600 a$ & 134.7 & 58.1 & 20892.1 & 90.0 & 127.4 & -8.1 & 61.3 \\
\hline 24 & $R-142 b$ & 137.1 & 100.5 & 22268.7 & 79.3 & 118.3 & -6.5 & 63.3 \\
\hline 25 & R-236a & 139.3 & 152.0 & 25867.9 & 118.3 & 173.1 & -5.1 & 65.1 \\
\hline 26 & R-114 & 145.7 & 170.9 & 23729.2 & 113.1 & 166.5 & -0.9 & 70.3 \\
\hline 27 & E134 & 147.1 & 118.0 & 26871.6 & 93.6 & 166.6 & 0.0 & 71.5 \\
\hline 28 & $R-600$ & 152.0 & 58.1 & 22192.4 & 95.3 & 134.9 & 3.2 & 75.5 \\
\hline 29 & R-143 & 156.7 & 84.0 & 25832.8 & 75.6 & 131.5 & 6.27 & 79.4 \\
\hline 30 & E-245 & 170.9 & 150.0 & 28204.5 & 132.5 & 187.3 & 15.5 & 91.0 \\
\hline 31 & R-21 & 178.5 & 102.9 & 24068.0 & 62.4 & 108.0 & 20.4 & 97.2 \\
\hline 32 & $\mathrm{R}-123$ & 183.8 & 152.9 & 26360.1 & 103.9 & 153.5 & 23.9 & 101.6 \\
\hline 33 & I-C5 & 187.4 & 72.2 & 24800.3 & 121.1 & 163.4 & 26.2 & 104.5 \\
\hline 34 & $R-123 a$ & 187.9 & 152.9 & 26520.6 & 105.5 & 158.9 & 26.6 & 105.0 \\
\hline 35 & $\mathrm{~N}-\mathrm{C} 5$ & 196.4 & 72.2 & 26027.2 & 123.7 & 168.0 & 32.1 & 111.9 \\
\hline 36 & $\mathrm{R}-11$ & 198.1 & 137.4 & 24342.9 & 80.9 & 121.4 & 33.1 & 113.2 \\
\hline 37 & R-141b & 204.2 & 116.9 & 25785.6 & 92.0 & 137.9 & 37.1 & 118.3 \\
\hline 38 & R-113 & 214.3 & 187.4 & 27164.1 & 123.1 & 169.6 & 43.7 & 126.6 \\
\hline
\end{tabular}

${ }^{*}$ evaluated at $\mathrm{T}_{\mathrm{r}}=0.65$ 


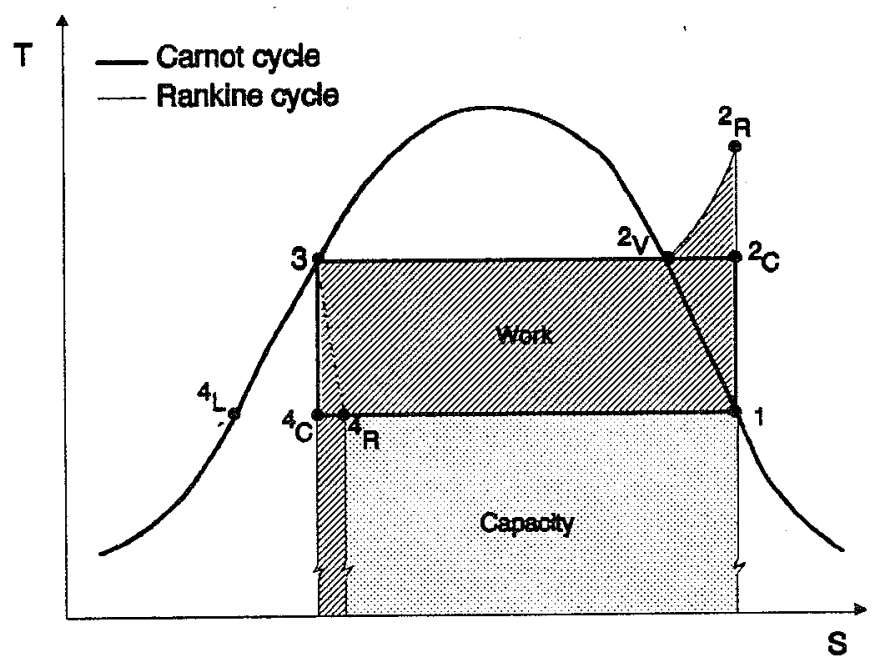

Figure 1. Carnot and Rankine cycle

(work and capacity marked for the Rankine cycle)

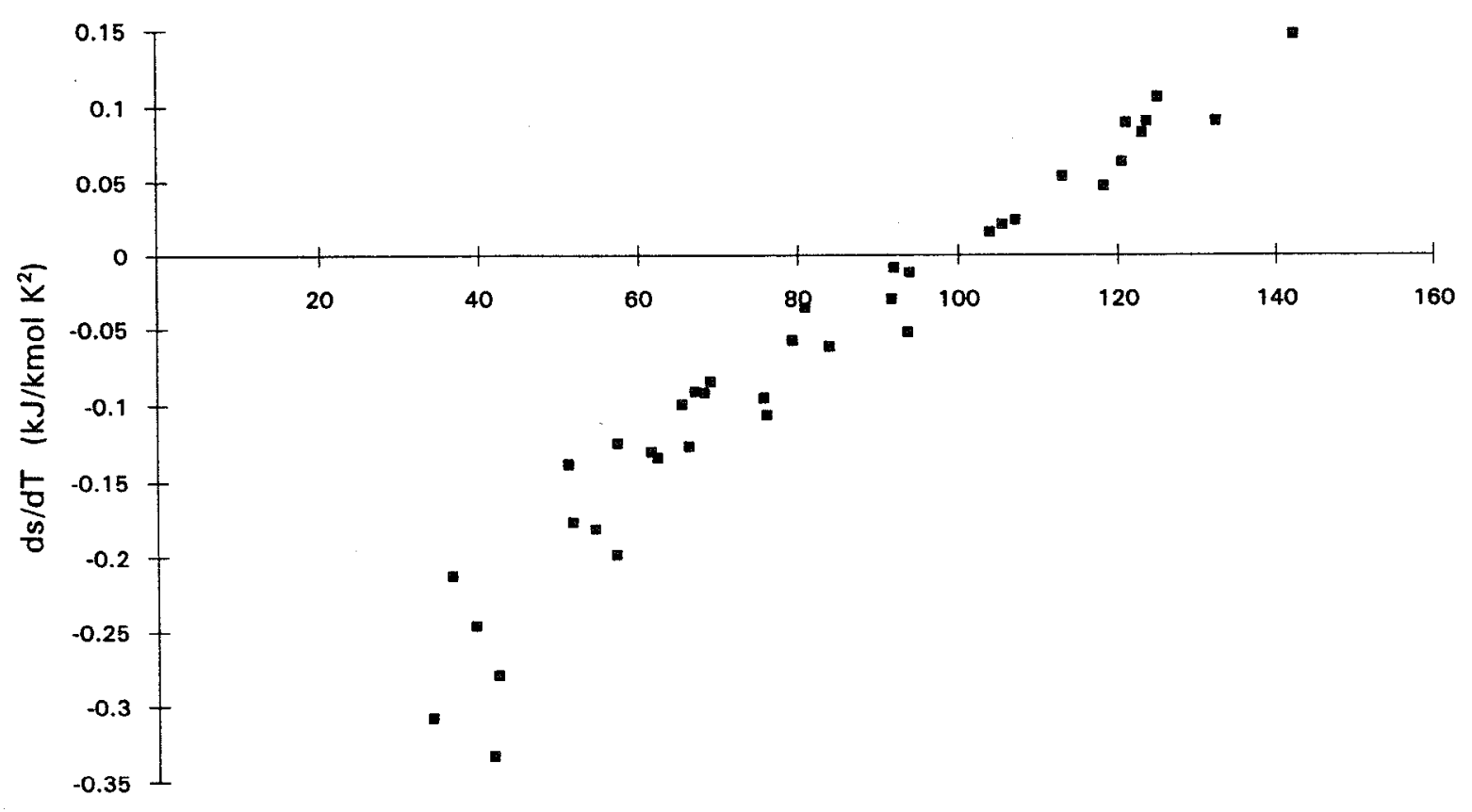

Vapor molar heat capacity $\quad(\mathrm{kJ} / \mathrm{kmol} \mathrm{K})$

Figure 2. Reciprocal of the slope of saturated vapor line (ds/dT) on T-S diagram at $T_{r}=0.65$ for 38 fluids of Table 1 
As opposed to the Carnot cycle, the Rankine cycle incorporates some of the irreversibilities of a real vapor compression system. Specifically, refrigerant superheating at the end of compression (point $2_{R}$ ) and the isenthalpic (non-isentropic) expansion process $\left(3-4_{R}\right.$ ). Because of its inherent irreversibilities, the COP of the Rankine cycle is lower than that of the Carnot cycle. In contrast to the fluid-insensitive Carnot cycle, the fluid thermodynamic properties will cause the Rankine cycle to have a fluid-dependent COP.

The suitability of refrigerant thermodynamic properties can be inferred from the slopes of the liquid and vapor saturation lines on temperature-entropy coordinates. Ideally, both lines should be vertical. In reality, the slope of the saturated vapor line may be either positive or negative, while only a positive slope is possible for the saturated liquid line [2]. On the compression side, a positively sloped saturation line would cause the end state of the compression process to lie within the two-phase region. This is an undesired condition for a positive displacement compressor. With a negative slope, excessive compression work is required. On the expansion side, the saturation line's gradient is related to the part of the evaporator capacity that is lost due to liquid flashing.

The slope of the saturation line on temperature-entropy coordinates can be represented with the equation proposed by Duffield and Hodgett [3]:

$$
\frac{d T}{d s}=\frac{T}{c_{p}-\beta \cdot h_{f g} \frac{v}{v_{v}-v_{1}}}
$$

For a given absolute temperature, the fluid properties in the denominator control the sign and magnitude of $d T / d s$. For the liquid saturation line, the small values of $\beta_{1}$ and $v_{l} /\left(v_{v}-v_{1}\right)$ cause the heat capacity to be the dominant term and ensures that $\mathrm{dT} / \mathrm{ds}$ is always positive. For the vapor saturation line, the term $v_{v} /\left(v_{v}-v_{1}\right)$ is approximately equal to one since $v_{v}$ $>>v_{1}$. When evaluated at the same reduced temperature $T_{r}=0.65$, the molar heat capacity of different fluids varies by a factor of four. Although the latent heat, $h_{f g}$, also varies significantly (by a factor of two), the term $\beta_{\mathrm{v}} \cdot \mathrm{h}_{\mathrm{fg}} \cdot \mathrm{v}_{\mathrm{v}} /\left(\mathrm{v}_{\mathrm{v}}-\mathrm{v}_{\mathrm{v}}\right)$ is contained in a narrow band $-10 \%$ to $+11 \%$ from the average value for all the fluids. This causes the molar heat capacity to be the most influential term on the slope of the vapor saturation line. The molar heat capacity's effect on dT/ds for the vapor saturation line is graphically depicted in Figure 2 .

Most of the cycle simulations in this study were performed at the evaporator and condenser reduced temperatures of $T_{\text {evap, },}=0.65$ and $T_{\text {cond, } r}=0.82$. This allowed examining a diverse set of refrigerants (all 38 fluids covered by REFPROP) at their best operating temperature range, while still testing them against the same COP limit of the Carnot cycle. Keeping the reduced temperatures constant for different fluids results in different absolute temperatures and temperature lift. 
In addition to the evaluations based on reduced temperatures, several simulations were also conducted at assigned absolute temperatures in the evaporator and condenser, $\mathrm{T}_{\text {evap }}=8^{\circ} \mathrm{C}$ and $\mathrm{T}_{\text {cond }}=46^{\circ} \mathrm{C}$, which are representative of refrigerant temperatures for a residential airconditioning application. The simulations based on absolute temperatures result in different evaporator and condenser pressures between screened fluids. Refrigerants 14, 23, 13, and 744 were excluded from these simulations because the specified $46^{\circ} \mathrm{C}$ saturation temperature in the condenser was above the critical temperature for these fluids.

\section{Rankine Cycle}

In this section we will examine the performance of various refrigerants in the reversed Rankine cycle. Although the Rankine cycle has been extensively examined in the literature, a short coverage of the topic is given here for completeness.

Refer to Figure 1 which displays the Rankine and Carnot cycles on temperature-entropy coordinates. It follows from the definition of entropy, $\mathrm{Tds}=\mathrm{Q}$, that the area under a reversible-process line represents the heat transferred to or from the refrigerant during the process. Combining this with the First Law of Thermodynamics, the work input to the cycle is shown in Figure 1 as the enclosed area. The non-overlapping areas of the two cycles indicate a loss in the refrigerating capacity and an increase in the work required for the Rankine cycle over the Carnot cycle.

For the Carnot cycle, the refrigerating capacity is represented by the area under the line ${ }^{4} \mathrm{C}^{-1}$, and the work is outlined by the rectangle $1-2 \mathrm{C}^{-3}-4_{C}$. The work for the Rankine cycle includes that for the Carnot cycle plus the work depicted by the triangle $2 \mathrm{C}^{-2}-2_{\mathrm{V}}$ and the rectangle located under the line $4_{C}-4{ }_{R}$. The first area represents the additional work required due to vapor superheating above the temperature of the heat sink, while the second corresponds to the work needed to compensate for the irreversible expansion process $3-4_{R}$. The area under the line $4_{C}-4_{R}$ also represents the loss of refrigerating capacity. Hence, the irreversible expansion causes an equal loss of refrigerating capacity as it increases the needed cycle work.

Based on these observations from Figure 1, we can write the following equations for the Rankine cycle capacity, work, and $\mathrm{COP}_{\mathrm{R}}$ :

$$
\begin{gathered}
\mathrm{Q}_{\mathrm{R}}=\mathrm{Q}_{\mathrm{C}}-\mathrm{Q}_{\text {exp }} \\
\mathrm{W}_{\mathrm{R}}=\mathrm{W}_{\mathrm{C}}+\mathrm{W}_{\text {exp }}+\mathrm{W}_{\text {sup }} \\
\mathrm{COP}_{\mathrm{R}}=\frac{\mathrm{Q}_{\mathrm{R}}}{\mathrm{W}_{\mathrm{R}}}=\mathrm{COP}_{\mathrm{C}} \frac{1-\frac{\mathrm{Q}_{\text {exp }}}{\mathrm{Q}_{\mathrm{C}}}}{1+\frac{\mathrm{W}_{\text {exp }}}{\mathrm{W}_{\mathrm{C}}}+\frac{\mathrm{W}_{\text {sup }}}{\mathrm{W}_{\mathrm{C}}}}
\end{gathered}
$$


The last equation represents the coefficient of performance of the Rankine cycle in terms of the $\mathrm{COP}_{\mathrm{C}}$ and the multiplier, which is always smaller than one.

We can evaluate $\mathrm{Q}_{\exp } / \mathrm{Q}_{C}$ in a few steps using simplifying assumptions. Considering that liquid isobars almost coincide with the saturated liquid line on the temperature-entropy diagram, we can calculate the entropy change between points $4_{R}$ and $4_{L}$ by the following equation:

$$
s_{4 R}-s_{4 L} \approx \frac{\bar{c}_{p, 1}\left(T_{\text {cond }}-T_{\text {evap }}\right)}{T_{\text {evap }}}
$$

where $\bar{c}_{p, 1}$ is the average heat capacity of the liquid for the temperature interval $T_{\text {cond }}-T_{\text {evap }}$. We can also calculate the entropy change between point $4_{C}$ and $4_{L}$ as follows:

$$
s_{4 C}-s_{4 L}=s_{3}-s_{4 L} \approx \int \frac{c_{p, l}}{T} d T=\bar{c}_{p, 1} \ln \frac{T_{\text {cond }}}{T_{\text {evap }}}
$$

Combining and multiplying by the evaporator temperature, we can obtain a relation for the refrigerating capacity loss due to isenthalpic expansion:

$$
Q_{\text {exp }}=\left(s_{4 R}-s_{4 C}\right) T_{\text {evap }}=\bar{c}_{p, 1}\left(T_{\text {cond }}-T_{\text {evap }}-T_{\text {evap }} \ln \frac{T_{\text {cond }}}{T_{\text {evap }}}\right)
$$

The capacity of the Carnot cycle can be expressed in terms of the latent heat and enthalpy change between points $4_{C}$ and $4_{L}$ :

$$
Q_{C}=h_{f g}-T_{\text {evap }}\left(s_{4 C}-s_{4 L}\right)=h_{f g}-T_{\text {evap }} \bar{c}_{p, 1} \ln \frac{T_{\text {cond }}}{T_{\text {evap }}}
$$

By combining the relations for $Q_{\text {exp }}$ and $Q_{c}$, and rearranging, we obtain the following expression for the relative loss of refrigerating capacity due to isenthalpic expansion: 


$$
\frac{Q_{\text {exp }}}{Q_{C}}=\frac{\frac{1}{\operatorname{COP}_{C}}-\ln \frac{T_{\text {cond }}}{T_{\text {evap }}}}{\frac{h_{f g}}{T_{\text {evap }} \bar{c}_{p, 1}}-\ln \frac{T_{\text {cond }}}{T_{\text {evap }}}}
$$

At this point, we may comment that the relative loss of work due to isentropic expansion, $\mathrm{W}_{\mathrm{exp}} / \mathrm{W}_{\mathrm{C}}$, is related to $\mathrm{Q}_{\mathrm{exp}} / \mathrm{Q}_{\mathrm{C}}$ through the Carnot efficiency:

$$
\frac{\mathrm{W}_{\text {exp }}}{\mathrm{W}_{\mathrm{C}}}=\frac{\mathrm{Q}_{\mathrm{exp}}}{\mathrm{Q}_{\mathrm{C}}} \mathrm{COP}_{\mathrm{C}}
$$

since $\mathrm{W}_{\exp }=\mathrm{Q}_{\mathrm{exp}}$ and $\mathrm{W}_{\mathrm{C}}=\mathrm{Q}_{\mathrm{C}} / \mathrm{COP}_{\mathrm{C}}$.

Only one term in the derived relation for $\mathrm{Q}_{\mathrm{exp}} / \mathrm{Q}_{\mathrm{C}}$ is fluid-property dependent, while the remaining three terms depend on operating conditions. If we evaluate refrigerants at the same absolute or reduced temperatures in the evaporator and condenser, the three operating regime dependent terms will have the same values for all the fluids. Thus the relative loss of the refrigerating capacity will depend solely on the latent heat, heat capacity of liquid at constant pressure, and the absolute temperature in the evaporator.

If we consider the term $h_{f g} /\left(T_{e v a p} \cdot c_{p, l}\right)$ at a given reduced temperature, the ratio $h_{f g} / T_{\text {evap }}$ does not vary significantly between fluids. For all 38 refrigerants, the maximum deviation was found to be \pm 16 percent. The deviation of molar heat capacity is much larger (from $44 \%$ to $+52 \%$ ), as shown graphically in Figure 3, making the heat capacity the most significant variable in $\mathrm{h}_{\mathrm{fg}} /\left(\mathrm{T}_{\mathrm{evap}} \cdot \mathrm{c}_{\mathrm{p}, \mathrm{l}}\right)$. Figure 4 presents the relation between this term and $c_{p, v}$ at $T_{r}=0.65$ and average value of $c_{p, 1}$ calculated for $T_{r}=0.65$ and $T_{r}=0.82$. Since the vapor points appear to have less scatter, the molar heat capacity of vapor will be used as a convenient sorting criterion for refrigerants when their performance is evaluated at the same reduced temperatures. When refrigerant screening is performed at the same absolute temperatures, the term $\mathrm{h}_{\mathrm{fg}} / \mathrm{T}_{\text {evap }}$ is not that uniform between different refrigerants and will have to be included for refrigerant sorting.

It should be noted that the limited variation of $h_{\mathrm{fg}} / \mathrm{T}$, when evaluated for different fluids at the same reduced temperature, can be deduced from the way $\mathrm{h}_{\mathrm{fg}} / \mathrm{T}$ is correlated in the $0.6<\mathrm{T}_{\mathrm{r}}<1.0$ range with the Pitzer acentric factor, $\omega$ [4]:

$$
\frac{h_{\mathrm{fg}}}{T}=\frac{R}{T_{r}}\left[7.08\left(1-T_{r}\right)^{0.354}+10.95 \omega\left(1-T_{r}\right)^{0.456}\right]
$$

where $\omega=-\log _{10}\left(\mathrm{P}_{0.7} / \mathrm{P}_{\text {crit }}\right)-1$ does not significantly influence the result. 


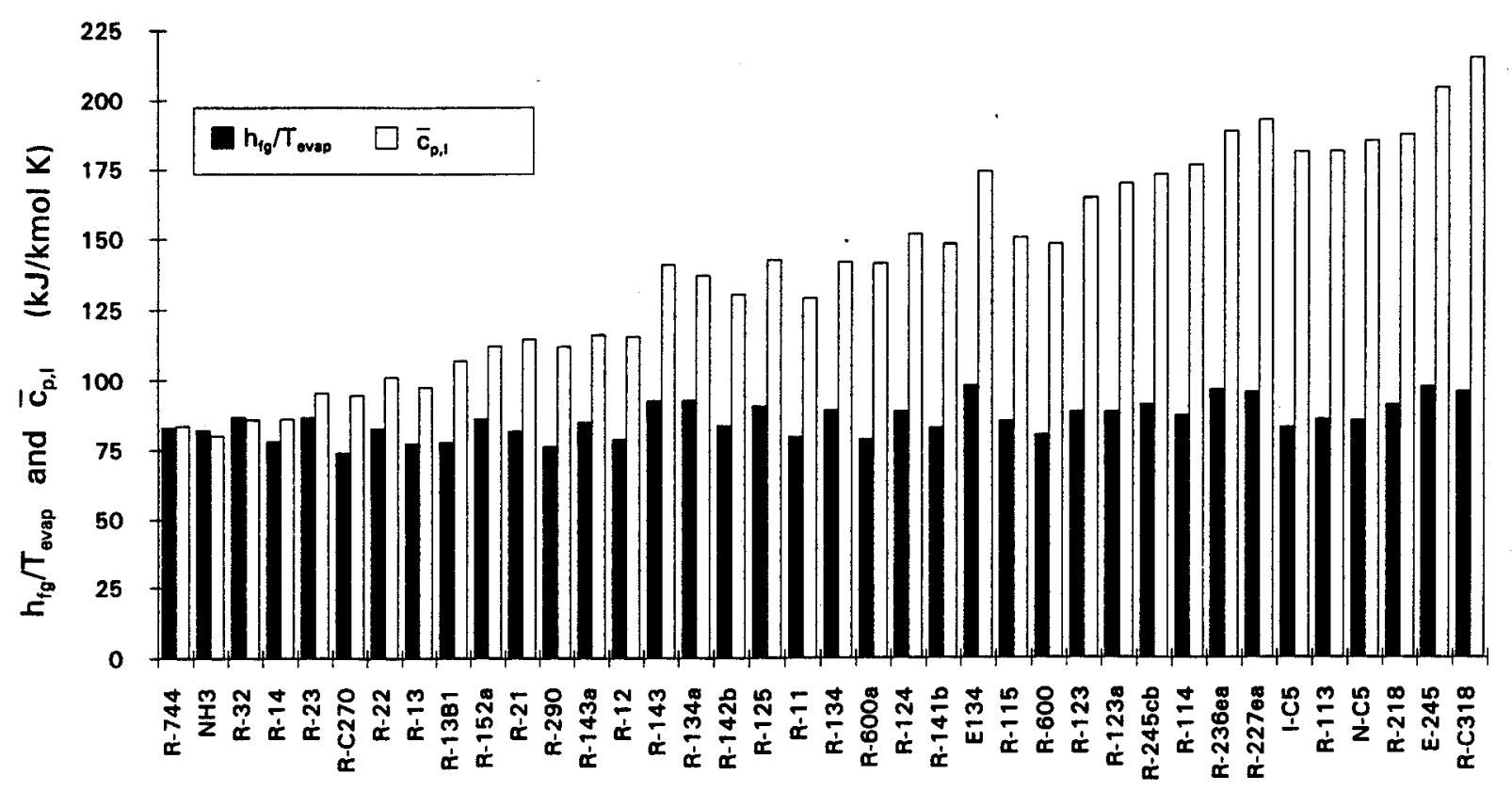

Figure 3. Values of $h_{\mathrm{fg}} / \mathrm{T}_{\text {evap }}\left(\mathrm{at} \mathrm{T}_{\mathrm{r}}=0.65\right)$ and $\bar{c}_{\mathrm{p}, \mathrm{l}}$ (average value of heat capacity at $T_{r}=0.65$ and 0.82 , refrigerants sorted by $c_{p, v}$ at $T_{r}=0.65$.)

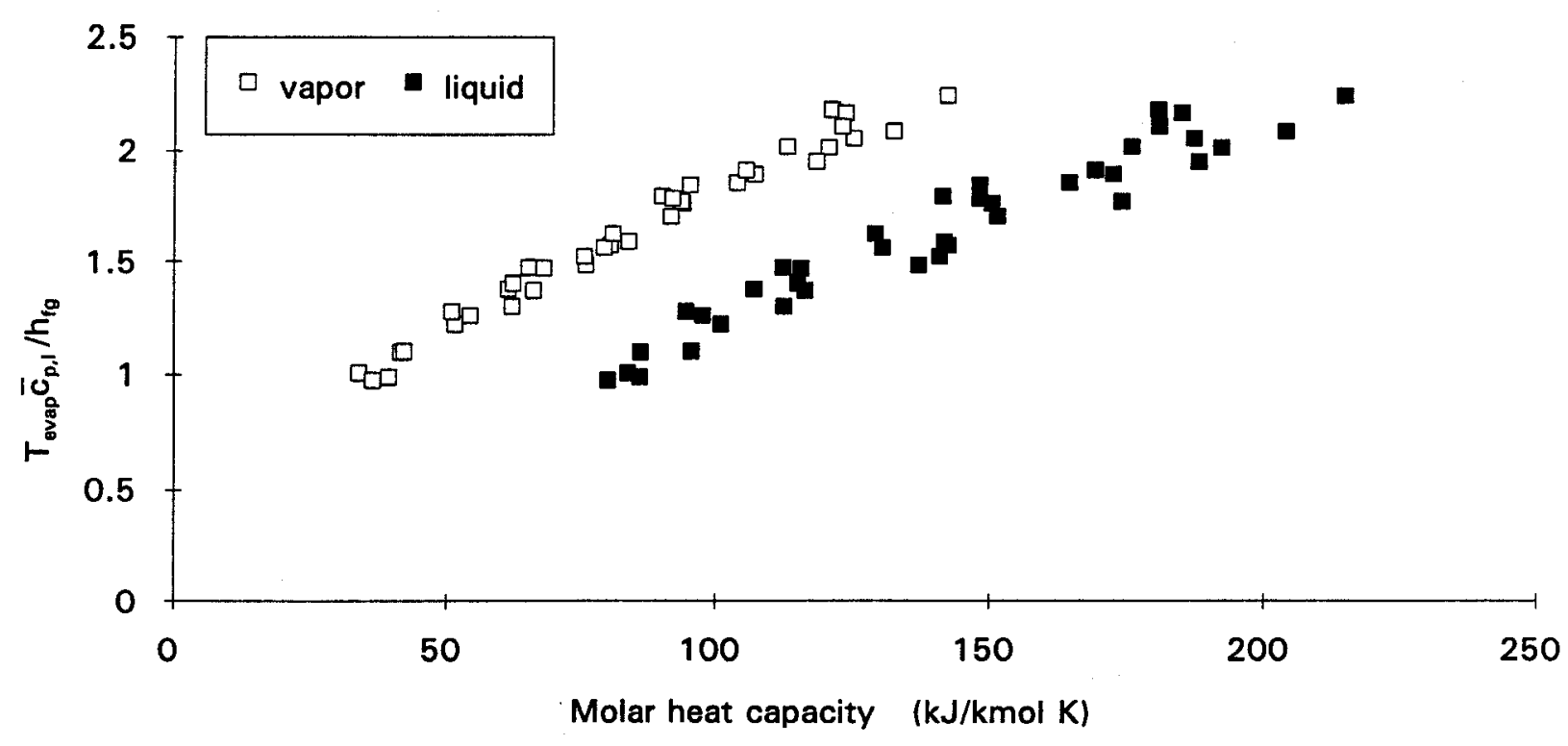

Figure 4. Relation between $\mathrm{T}_{\text {evap }} \overline{\mathrm{c}}_{\mathrm{p}, \mathrm{l}} / \mathrm{h}_{\mathrm{fg}}$ and molar heat capacity of liquid and vapor $\left(\mathrm{T}_{\text {evap }}, \mathrm{h}_{\mathrm{fg}}, \mathrm{c}_{\mathrm{p}, \mathrm{v}}\right.$ evaluated at $\mathrm{T}_{\mathrm{r}}=0.65, \quad \overline{\mathrm{c}}_{\mathrm{p}, \mathrm{l}}$ is the average of heat capacities at $T_{r}=0.65$ and 0.82 ) 


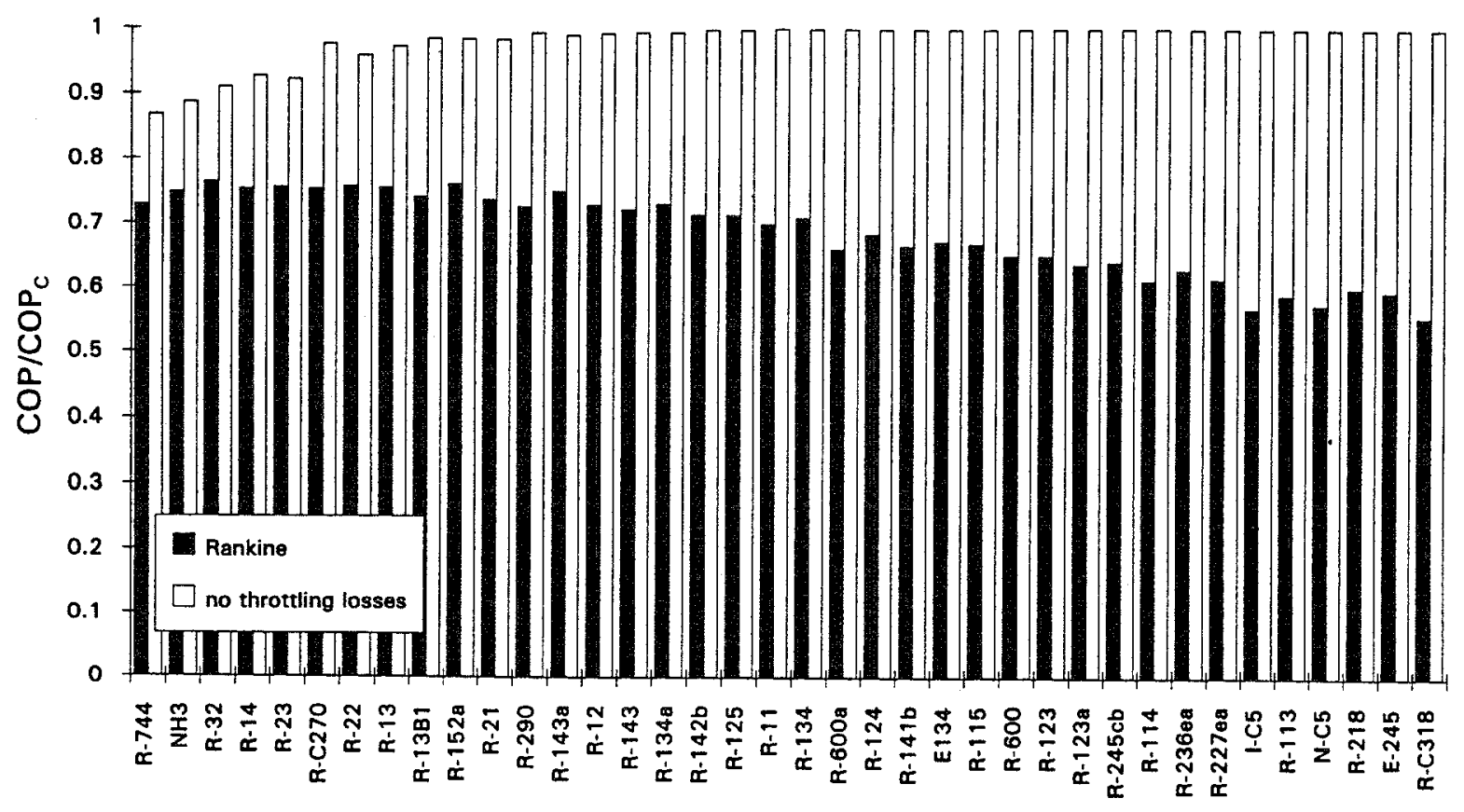

Figure 5. COP of the Rankine cycle and the cycle with no throttling irreversibilities referenced to $\operatorname{COP}_{C}\left(T_{\text {evap }, \mathrm{r}}=0.65, \mathrm{~T}_{\text {cond,r }}=0.82\right.$, refrigerants sorted by $\mathrm{c}_{\mathrm{p}, \mathrm{v}}$ at $T_{r}=0.65$ )

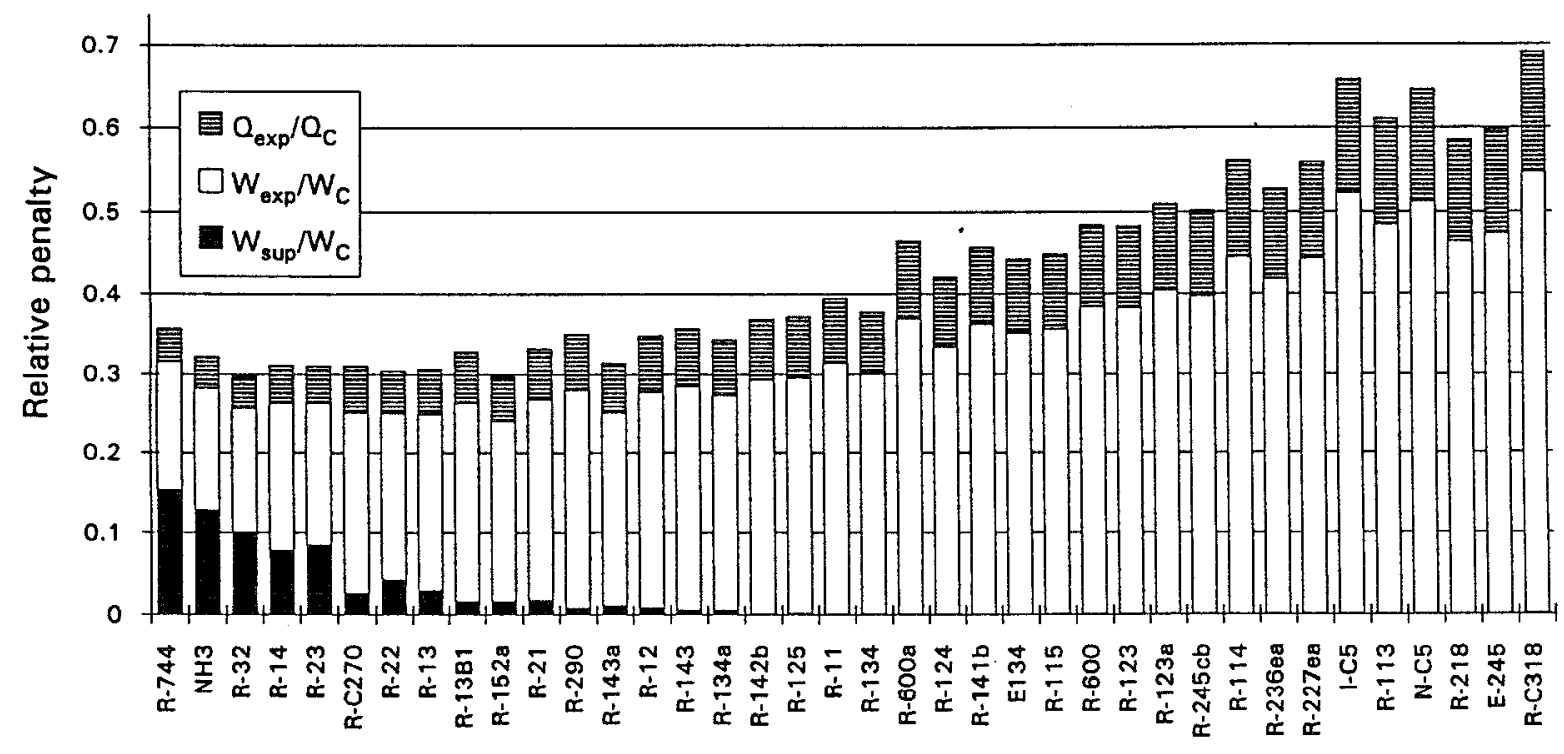

Figure 6. Relative penalties degrading the Rankine cycle COP $\quad\left(\mathrm{T}_{\text {evap, } \mathrm{r}}=0.65\right.$, $\mathrm{T}_{\text {cond, } \mathrm{r}}=0.82$, refrigerants sorted by $\mathrm{c}_{\mathrm{p}, \mathrm{v}}$ at $\mathrm{T}_{\mathrm{r}}=0.65$ ) 
Figures 5 and 6 present results of simulations performed for a Rankine cycle defined by isentropic compression, isenthalpic expansion, and saturation temperatures in the condenser and evaporator. Condenser subcooling and evaporator superheat were specified zero. The temperatures in the evaporator and condenser were $0.65 \cdot \mathrm{T}_{\text {crit }}$ and $0.82 \cdot \mathrm{T}_{\text {crit }}$, respectively. The Carnot COP for these conditions is

$$
\operatorname{COP}_{C}=\frac{T_{\text {evap }}}{T_{\text {cond }}-T_{\text {evap }}}=\frac{0.65 \mathrm{~T}_{\text {crit }}}{(0.82-0.65) \mathrm{T}_{\text {crit }}}=3.82
$$

Figure 5 presents the ratio of different refrigerant COPs to this Carnot $\mathrm{COP}_{\mathrm{C}}$. The black bars represent the COP of the Rankine cycle (as shown in Figure 1), while the unshaded bars represent the COP for a cycle with the superheated vapor horn and with isentropic (not isenthalpic) expansion. The difference between the two COPs indicates the impact of isenthalpic expansion losses on the cycle COP. In general, small heat capacity refrigerants have a higher COP than refrigerants with a large heat capacity. Most of the COP penalty comes from the throttling losses, particularly for fluids having a larger heat capacity.

The penalties degrading the Rankine cycle $\mathrm{COP}_{\mathrm{R}}$ relative to the Carnot cycle, $\mathrm{Q}_{\exp } / \mathrm{Q}_{\mathrm{C}}$, $\mathrm{W}_{\text {exp }} / \mathrm{W}_{\mathrm{C}}$, and $\mathrm{W}_{\text {sup }} / \mathrm{W}_{\mathrm{C}}$, are presented in Figure 6 . For simplicity, these penalties are graphed on one bar for each fluid, though they do not have a straight additive effect on the COP. The terms $\mathrm{Q}_{\text {exp }} / \mathrm{Q}_{\mathrm{C}}$ and $\mathrm{W}_{\text {exp }} / \mathrm{W}_{\mathrm{C}}$ differ by a factor approximately equal to $\mathrm{COP}_{\mathrm{C}}$, which we have already deduced in this chapter. Fluids of large heat capacity do not have superheated-horn losses (compression process ends in the wet-vapor region), but they have the largest total losses due to throttling. Overall, the penalties caused by the isenthalpic expansion constitute the largest part of the total losses, and its share of the total penalty increases with molar heat capacity. Thus, minimizing these losses is an interesting challenge in the quest for improving the COP of the vapor compression cycle.

\section{Cycle with Liquid-Line/Suction-Line Heat Exchanger}

The cycle with a liquid-line/suction-line heat exchanger (llsl-hx) is probably the most common variation of the Rankine refrigeration cycle in practice. In the llsl-hx cycle, a heat exchanger is installed to subcool the high-pressure refrigerant with the low-pressure suction vapor, which is being superheated in the process. Figure 7 shows the schematic of the arrangement for the basic and llsl-hx cycle, and Figure 8 presents both cycles on the pressure-enthalpy diagram. The lisl-hx cycle has been studied by several researchers. The pertinent publications and theoretical analysis are included in reference [5]. The essence of this analysis is given below.

Addition of the liquid-line/suction-line heat exchanger to the Rankine cycle may have positive or negative performance implications. Figure 9 presents an example of the impact of the llsl$\mathrm{hx}$ on the COP calculated for four different refrigerants. The ordinate is the ratio of COP 

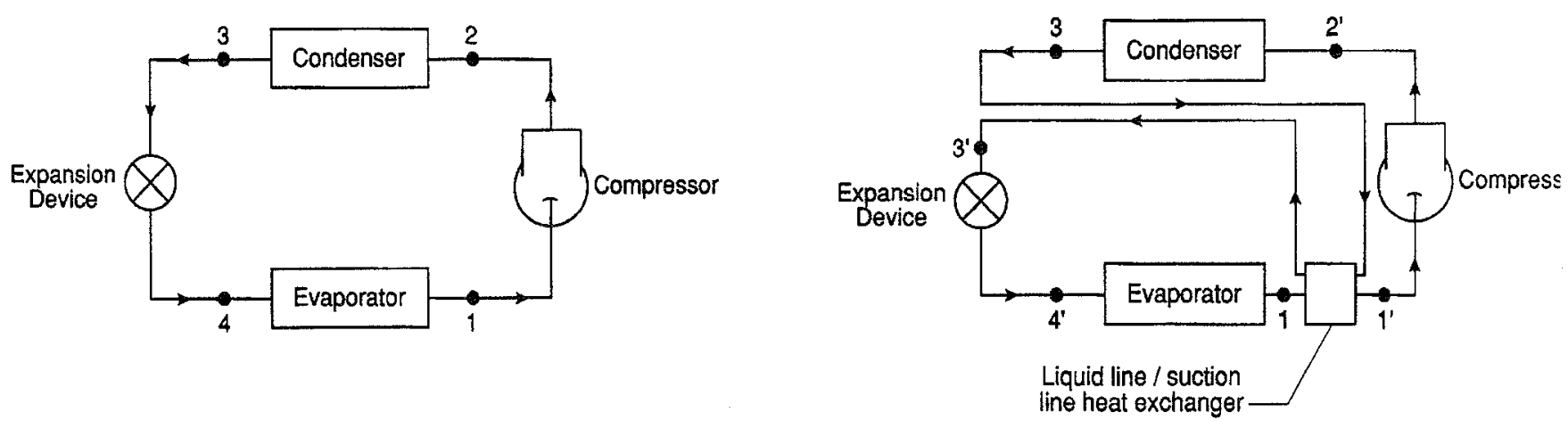

Figure 7. Schematic of hardware arrangements for the basic cycle and cycle with the liquid-line/suction-line heat exchanger.

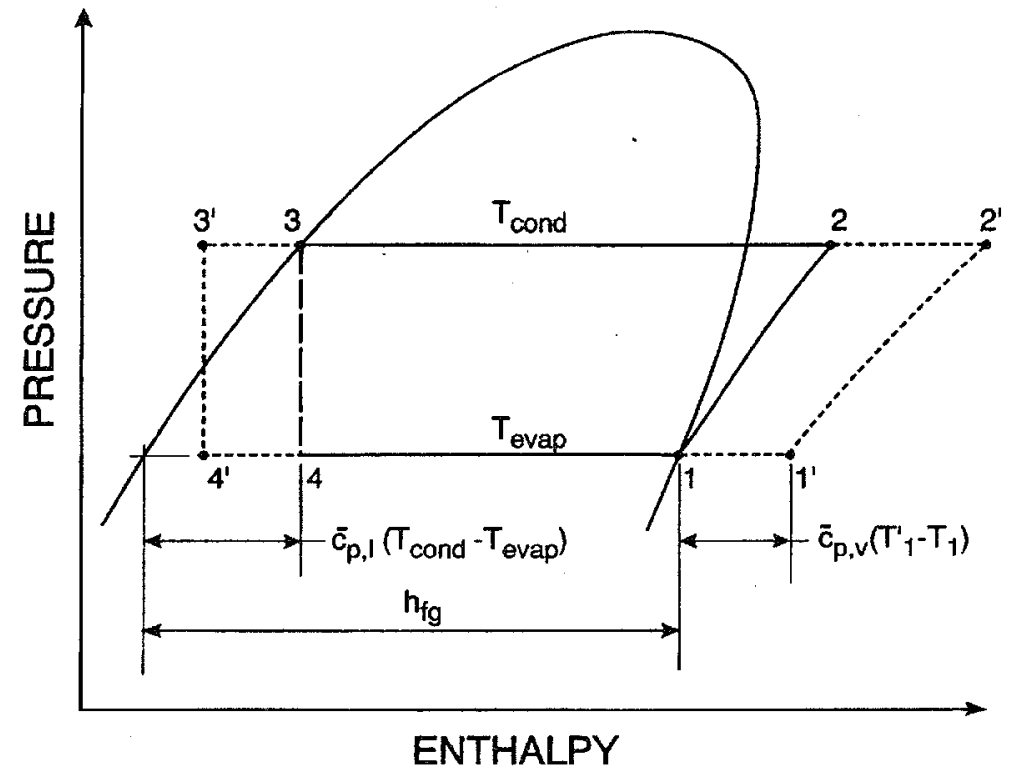

Figure 8. Key refrigerant state points in the basic cucle and llsl-hx cycle 


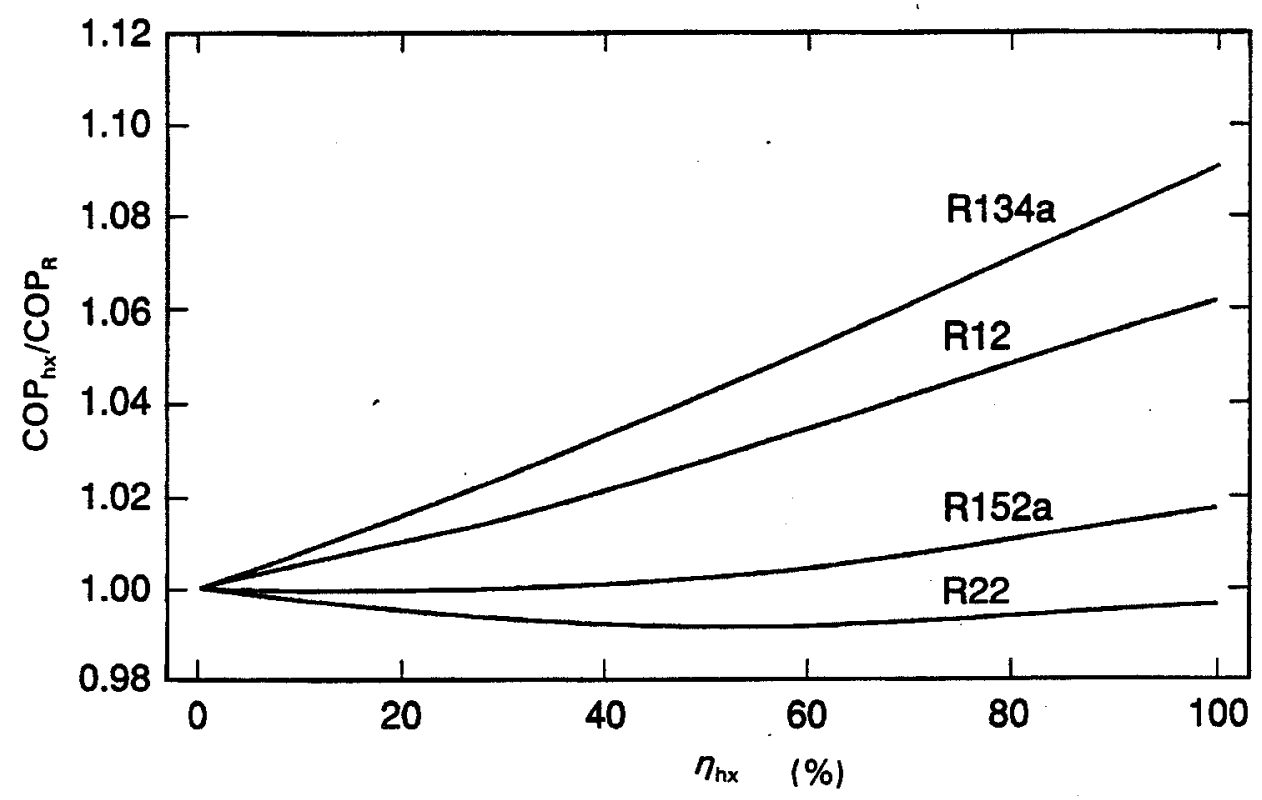

Figure 9. Change of the $\mathrm{COP}_{\mathrm{hx}}$ at different effectiveness of the llsl-hx at $\mathrm{T}_{\text {evap }}=-23^{\circ} \mathrm{C}$ and $\mathrm{T}_{\text {cond }}=42.5^{\circ} \mathrm{C}$

[5]

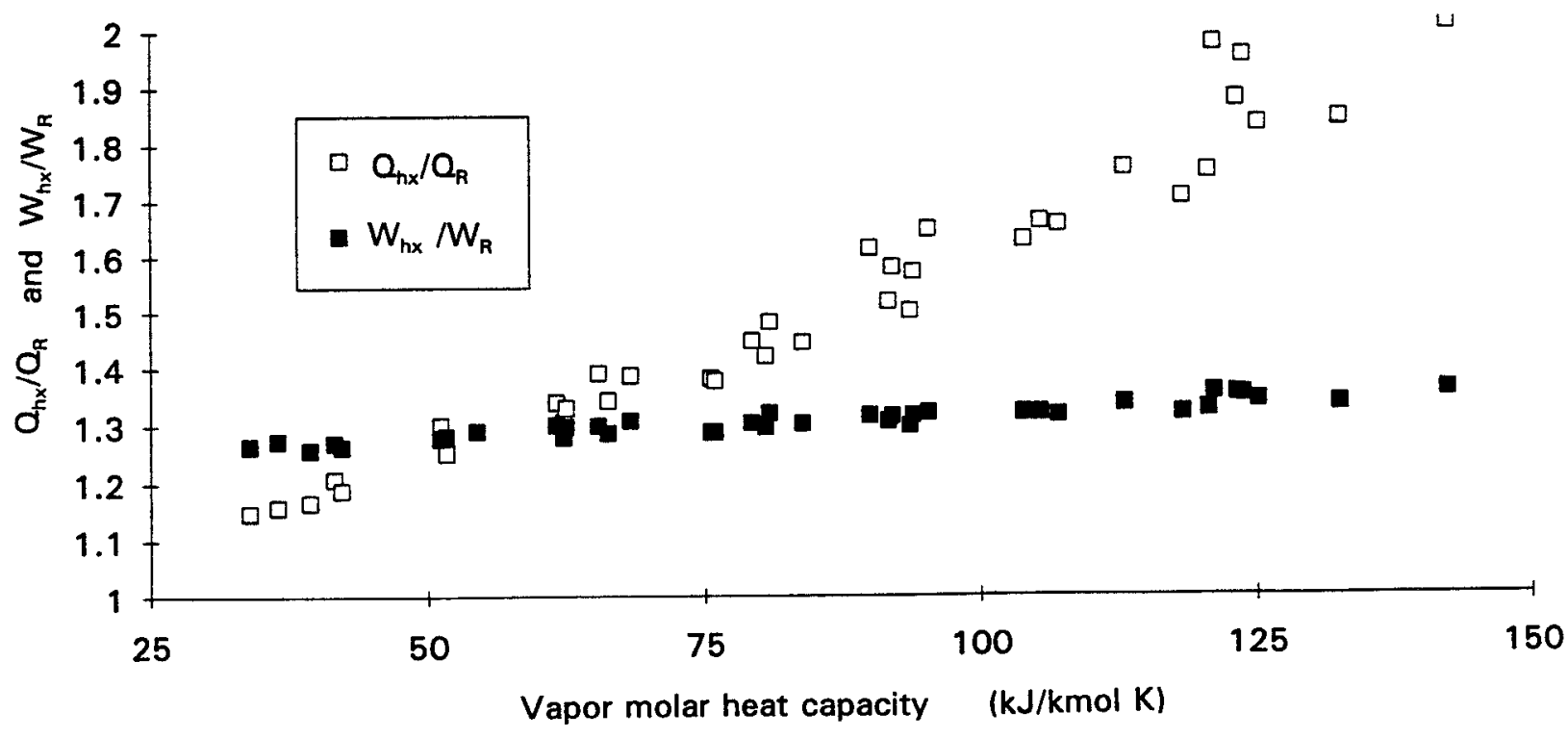

Figure 10. Capacity and work of the llsl-hx cycle referenced to capacity and work of the Rankine $\left(\mathrm{T}_{\text {evap }, \mathrm{r}}=0.65, \mathrm{~T}_{\text {cond, } \mathrm{r}}=0.82, \eta_{\mathrm{hx}}=1.0\right)$ 
obtained for a given llsl-hx effectiveness $\left(\eta_{\mathrm{hx}}\right)$ to the COP obtained for the same working fluid in the Rankine cycle $\left(\eta_{\mathrm{hx}}=0\right)$. For $\mathrm{R}-134 \mathrm{a}$, the increase in COP is the highest, as much as $9.1 \%$ percent at the theoretical limit of $100 \%$ effectiveness of the heat exchanger. For R-22, the llsl-hx causes degradation in COP at low values of the llsl-hx effectiveness, some of which is recovered at $100 \%$ effectiveness.

The ratio of the COP for the 1lsl-hx cycle and Rankine cycle may be expressed in terms of the ratios of capacities and work:

$$
\frac{\operatorname{COP}_{\mathrm{hx}}}{\operatorname{COP}_{\mathrm{R}}}=\frac{\frac{\mathrm{Q}_{\mathrm{hx}}}{\mathrm{Q}_{\mathrm{R}}}}{\frac{\mathrm{W}_{\mathrm{hx}}}{\mathrm{W}_{\mathrm{R}}}}
$$

For obvious reasons $\mathrm{Q}_{\mathrm{hx}} / \mathrm{Q}_{\mathrm{R}}$ is always greater than 1. Also, $\mathrm{W}_{\mathrm{hx}} / \mathrm{W}_{\mathrm{R}}$ is always greater than 1.0 since the slope of the constant-entropy line (which idealizes the compression process) decreases on the pressure-enthalpy diagram with increasing vapor superheat. Figure 10 presents these capacity and work ratios for the 38 studied fluids for theoretical limit of $100 \%$ effectiveness of the llsl-hx. The figure shows that the change in work required does not vary significantly for different fluids, but the change in capacity varies considerably with the molar heat capacity of vapor. Among other factors influencing the $\mathrm{COP}_{\mathrm{hx}}$ are the latent heat, coefficient of thermal expansion, temperature lift $\left(T_{\text {cond }}-T_{\text {evap }}\right)$, and amount of superheat resulting from the heat transfer between the liquid and suction line, as they appear in the following $\mathrm{COP}_{\mathrm{hx}} / \mathrm{COP}_{\mathrm{R}}$ relation [5]:

$$
\frac{\mathrm{COP}_{\mathrm{hx}}}{\mathrm{COP}_{\mathrm{R}}}=\frac{1+\frac{\overline{\mathrm{c}}_{\mathrm{p}, \mathrm{v}}\left(\mathrm{T}_{1}{ }^{\prime}-\mathrm{T}_{1}\right)}{\mathrm{h}_{\mathrm{fg}}-\overline{\mathrm{c}}_{\mathrm{p}, 1}\left(\mathrm{~T}_{\text {cond }}-\mathrm{T}_{\text {evap }}\right)}}{1+\frac{\mathrm{v}_{1}^{\prime}-\mathrm{v}_{1}}{\mathrm{v}_{1}}}=\frac{1+\frac{\mathrm{T}_{1}{ }^{\prime}-\mathrm{T}_{1}}{\mathrm{~h}_{\mathrm{fg}} / \overline{\mathrm{c}}_{\mathrm{p}, \mathrm{v}}-\left(\mathrm{T}_{\text {cond }}-\mathrm{T}_{\mathrm{evap}}\right) \overline{\mathrm{c}}_{\mathrm{p}, 1} / \overline{\mathrm{c}}_{\mathrm{p}, \mathrm{v}}}}{1+\bar{\beta}_{\mathrm{v}} \cdot\left(\mathrm{T}_{1}{ }^{\prime}-\mathrm{T}_{1}\right)}
$$

In the above equation, the latent heat is evaluated at the evaporator temperature, $\overline{\mathrm{c}}_{\mathrm{p}, \mathrm{l}}$ is the average heat capacity of liquid for the temperature interval $T_{\text {cond }}-T_{\text {evap }}$, and $\bar{c}_{p, v}$ is the heat capacity of vapor at the evaporator pressure in the temperature range $T_{1},-T_{1}$.

Figure 11 presents the coefficient of performance of the llsl-hx cycle, $\mathrm{COP}_{\mathrm{hx}}$, referenced to the COP of the Carnot cycle. Three bars are displayed for each fluid; the first one for heat exchanger effectiveness equal to zero (which constitutes the Rankine cycle), and the next two for the effectiveness equal to $50 \%$ and $100 \%$. The figure demonstrates two points:

1. Fluids of low heat capacity do not benefit from the installation of the llsl-hx, and perform better in the basic, unmodified Rankine cycle. For the fluids of very low heat capacity, the COP declines when the llsl-hx is installed. 


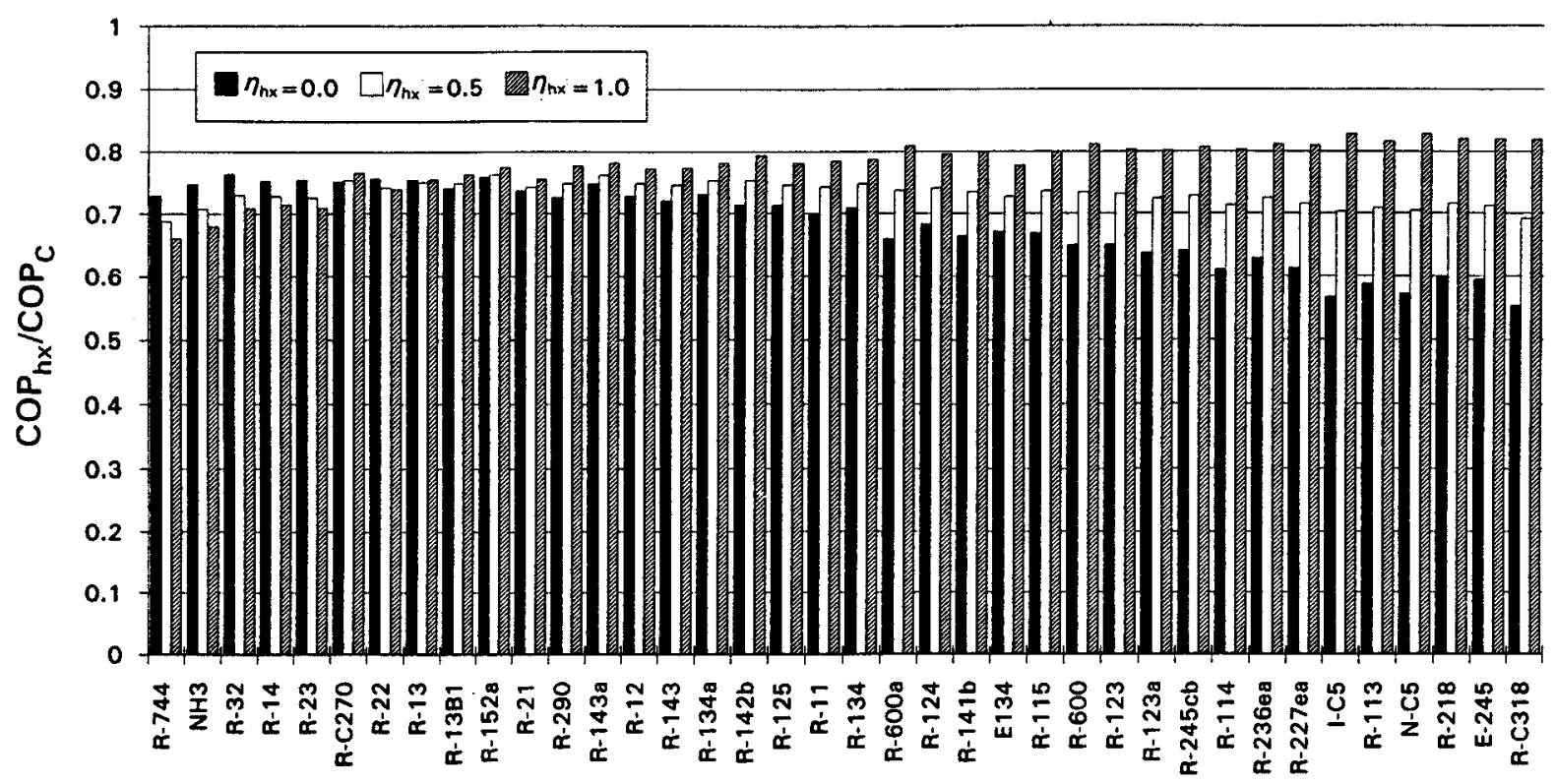

Figure 11. COP of the llsl-hx cycle referenced to $\operatorname{COP}_{c}\left(T_{\text {evap, },}=0.65, T_{\text {cond, }}=0.82\right.$, refrigerants sorted by $c_{p, v}$ at $T_{\text {evap }, r}$ )

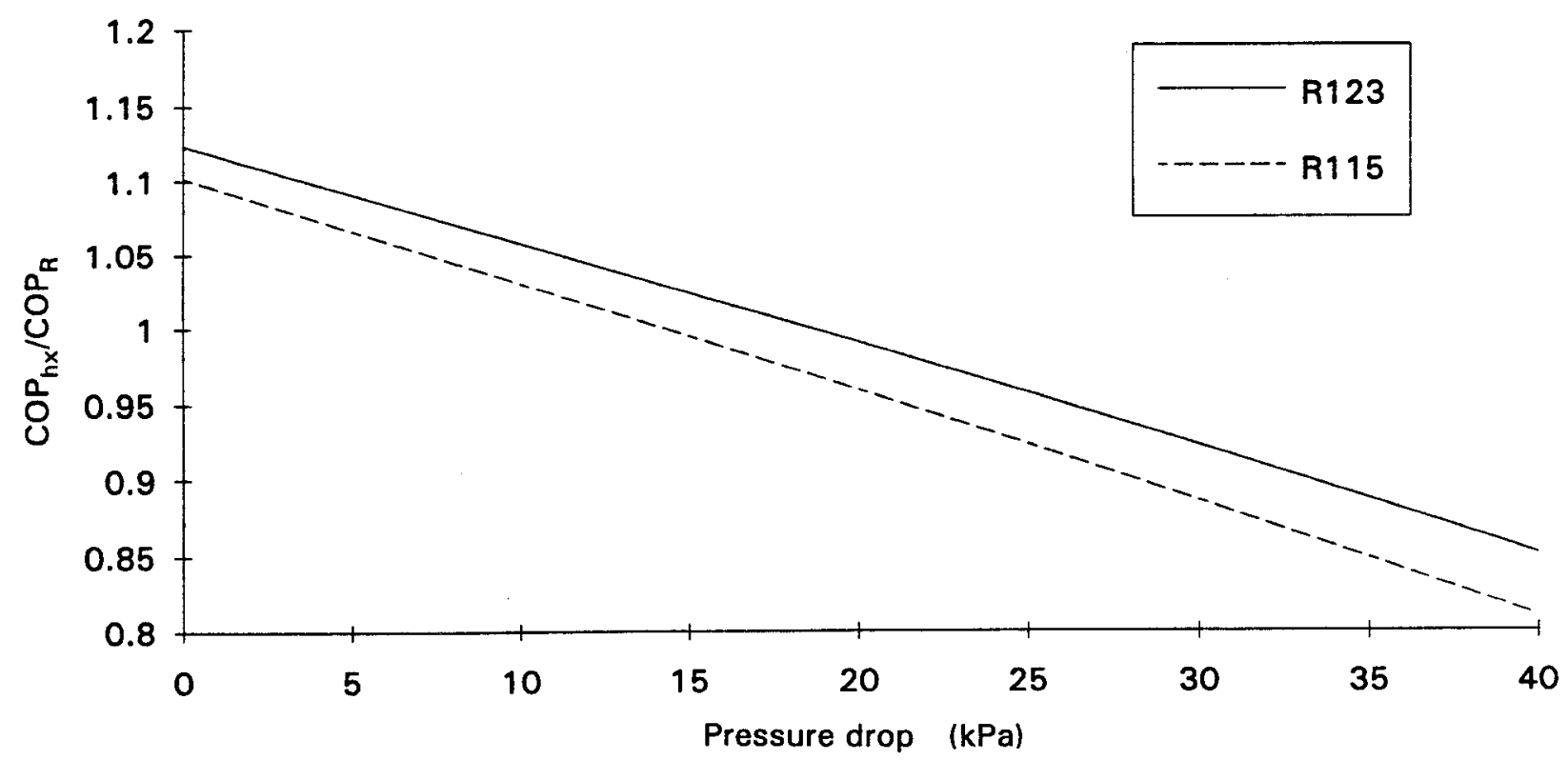

Figure 12. The effect of vapor-side pressure drop in llsl-hx on $\mathrm{COP}_{\mathrm{hx}}$ for $\mathrm{R}-123$ and R-125 ( $\mathrm{T}_{\text {evap, }}=0.65, \mathrm{~T}_{\text {cond, } \mathrm{r}}=0.82, \eta_{\mathrm{hx}}=0.5$ ) 
2. Fluids having a high molar heat capacity have a low COP in the Rankine cycle, but their performance improves with llsl heat exchange and can exceed the COP of the best performing fluids in the Rankine cycle at the theoretical limit of $100 \%$ effectiveness of the 1lsl-hx.

The COP improvement potential due to installation of the llsl-hx may be hampered by refrigerant pressure drop on the vapor side of llsl-hx. Figure 12 shows that $20 \mathrm{kPa}$ pressure drop totally eliminates the COP benefit of the $50 \%$ effective heat exchanger. Considering that the two refrigerants shown in Figure 12 (R-115 and R-123) have a similar pressure-drop penalty regardless of significantly different normal boiling points, the figure may be expected to be representative for other fluids. Refrigerant pressure drop on the liquid-line side of llsl$\mathrm{hx}$ showed no effect on the cycle performance.

Figure 13 shows simulated results for the assigned absolute temperatures in the evaporator and condenser of $8^{\circ} \mathrm{C}$ and $46^{\circ} \mathrm{C}$, respectively. The results are presented for refrigerants sorted in the ascending order of $\mathrm{T}_{\text {evap }} \cdot \overline{\mathrm{c}}_{\mathrm{p}, \mathrm{l}} / \mathrm{h}_{\mathrm{fg}}$, but the COP trend is not as consistent as in Figure 11. This is the effect of a significantly different superheated vapor horn and related additional compression work when the compression occurs between different reduced temperatures in the evaporator and condenser. When we consider the relative values of COP with and without llsl-hx, we can make the same observation from Figure 13 as from Figure 11 that only poor performing fluids in the Rankine cycle benefit from the liquid-line/suctionline heat exchange.

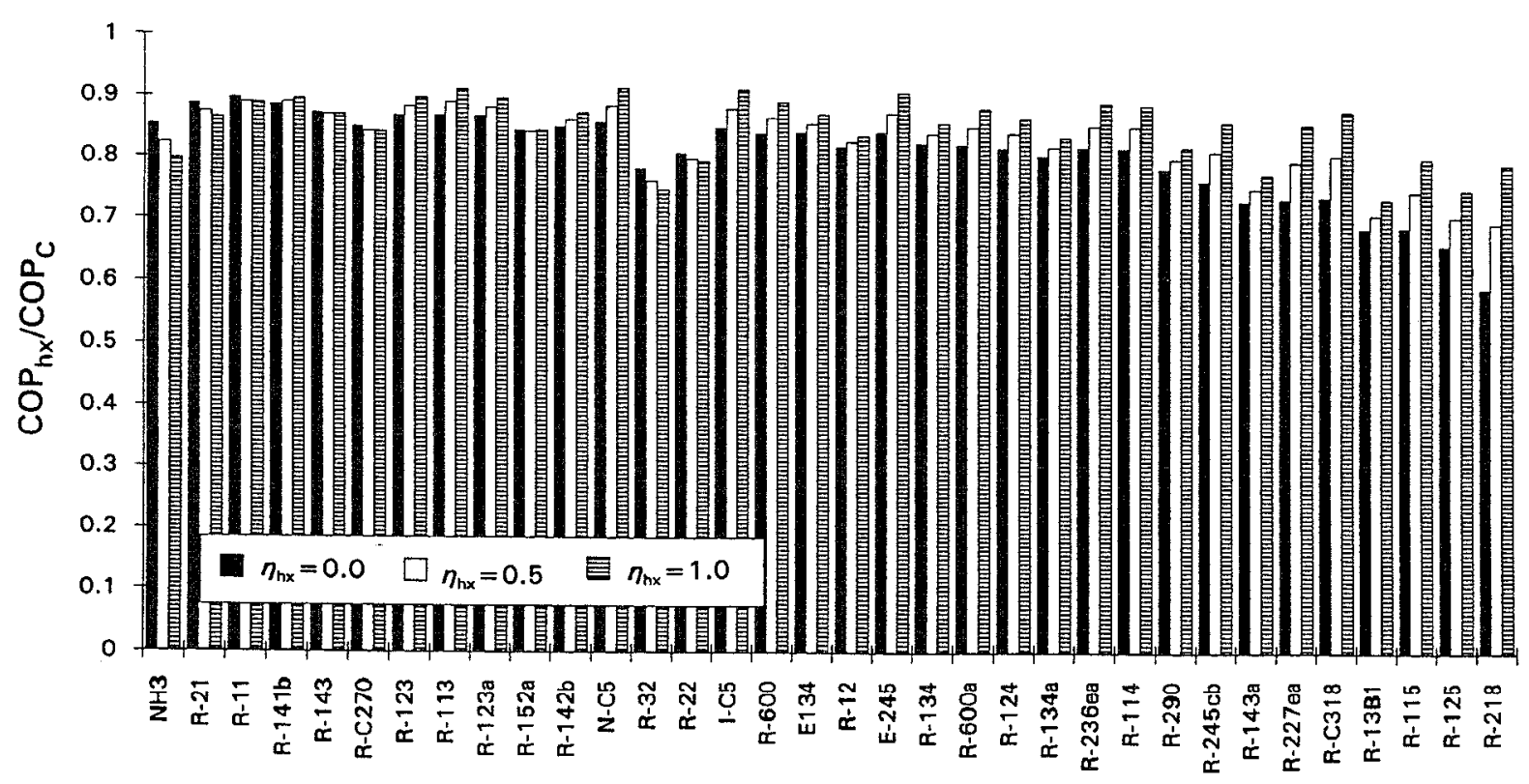

Figure 13. COP of the llsl-hx cycle referenced to $\mathrm{COP}_{\mathrm{C}}\left(\mathrm{T}_{\text {evap }}=8^{\circ} \mathrm{C}, \mathrm{T}_{\text {cond }}=46^{\circ} \mathrm{C}\right.$, refrigerant sorted by $\bar{c}_{\mathrm{p}, \mathrm{T}} \mathrm{T}_{\mathrm{evap}} / \mathrm{h}_{\mathrm{fg}}$ ) 


\section{Economizer Cycle}

The economizer refrigeration cycle differs from the Rankine cycle by a two-stage expansion with a liquid/vapor separator, and a compressor equipped with an intermediate-pressure suction port. In the economizer cycle (shown in Figures 14 and 15), the liquid and vapor phases are separated after the first-stage expansion; the vapor is fed to the intermediate stage of the compressor, and the liquid undergoes further expansion on its way to the evaporator. The flash gas existing at the intermediate pressure $\mathbf{P}_{\text {int }}$ is not allowed to expand to the evaporator pressure. Consequently, the compression work for this portion of the total refrigerant mass flow rate is lower, which results in a COP improvement for the economizer cycle.

We can relate the COP for the economizer cycle to the $\mathrm{COP}_{\mathrm{R}}$ by considering the Rankine cycle capacity and work and the differences in capacity and work between the economizer and Rankine cycle:

$$
\mathrm{COP}_{\mathrm{ECO}}=\frac{\mathrm{Q}_{\mathrm{ECO}}}{\mathrm{W}_{\mathrm{ECO}}}=\frac{\mathrm{Q}_{\mathrm{R}}+\Delta \mathrm{Q}_{\mathrm{ECO}}}{\mathrm{W}_{\mathrm{R}}+\Delta \mathrm{W}_{\mathrm{ECO}}}=\operatorname{COP}_{\mathrm{R}} \frac{1+\frac{\Delta \mathrm{Q}_{\mathrm{ECO}}}{\mathrm{Q}_{\mathrm{R}}}}{1+\frac{\Delta \mathrm{W}_{\mathrm{ECO}}}{\mathrm{W}_{\mathrm{R}}}}
$$

The COP improvement in the economizer cycle depends on the value of the $\mathrm{COP}_{\mathrm{R}}$ multiplier in the above equation. The denominator of this multiplier is always less than 1.0 because $\Delta \mathrm{W}_{\mathrm{ECO}}$ is negative. This results from the fact that in the economizer cycle not all refrigerant reaching the condenser has to be compressed from the evaporator pressure. Because it is difficult to intuitively predict the effect of the numerator, a derivation is helpful.

Using the assumptions stipulated in the section analyzing the llsl-hx, we can express the capacity of the Rankine and economizer cycle by the following relations:

$$
\begin{gathered}
Q_{E C O}=\left[h_{f g}-\bar{c}_{p, 1}\left(T_{\text {int }}-T_{\text {evap }}\right)\right]\left(1-x_{\text {int }}\right) \\
Q_{R}=h_{f g}-\bar{c}_{p, l}\left(T_{\text {cond }}-T_{\text {evap }}\right)
\end{gathered}
$$

where $T_{\text {int }}$ is the intermediate temperature and $x_{\text {int }}=\bar{c}_{p, l}\left(T_{\text {cond }}-T_{\text {int }}\right) / h_{f g, \text { int }}$ is the flow quality after the first-stage expansion. The difference in capacity between the Rankine and economizer cycle is then expressed by the equation:

$$
\Delta Q_{E C O}=Q_{E C O}-Q_{R}=\bar{c}_{p, 1}\left(T_{\text {cond }}-T_{\text {int }}\right)-\left[h_{f g}-\bar{c}_{p, 1}\left(T_{\text {int }}-T_{\text {evap }}\right)\right] x_{\text {int }}
$$




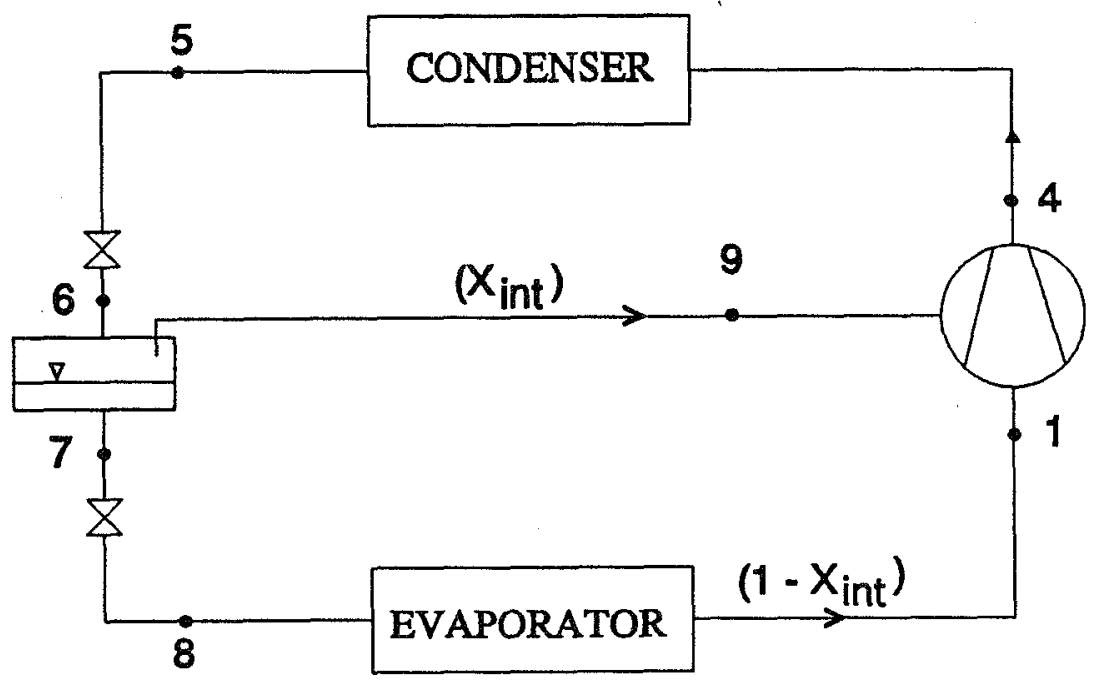

Figure 14. Schematic of the economizer system

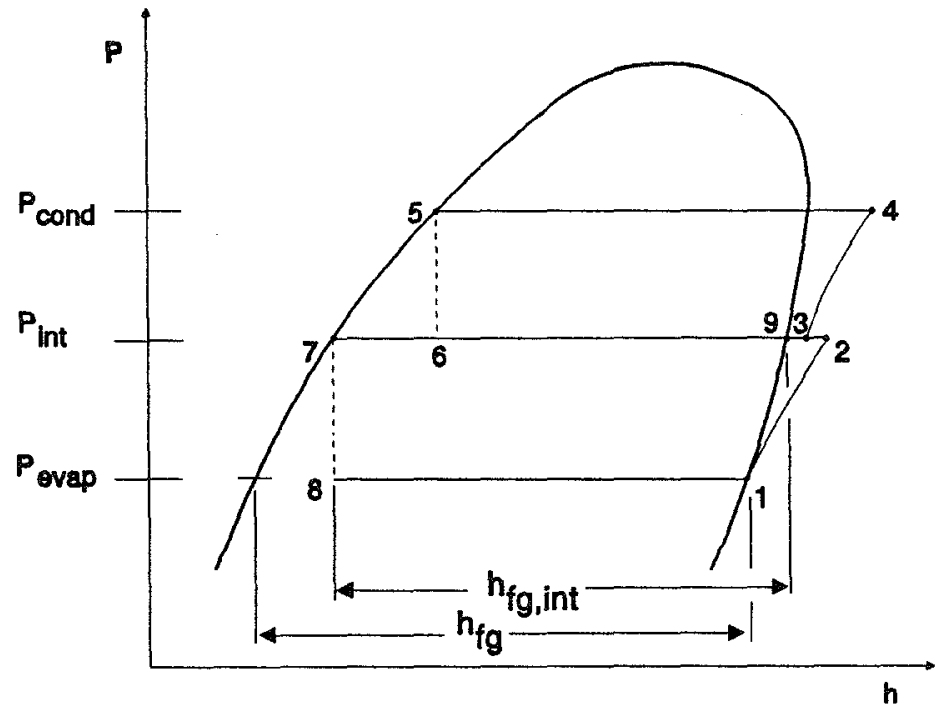

Figure 15. Pressure-enthalpy diagram for the economizer cycle 
If we use $x_{\text {int }}=\bar{c}_{p, l}\left(T_{\text {cond }}-T_{i n t}\right) / h_{f g, i n}$ and expand the above relation, we can see that the sign of $\Delta \mathrm{Q}_{\mathrm{ECO}}$ depends on the sign of the term $\mathrm{h}_{\mathrm{fg} \text {,int }}+\bar{c}_{\mathrm{p}, 1}\left(\mathrm{~T}_{\mathrm{int}}-\mathrm{T}_{\text {evap }}\right)-\mathrm{h}_{\mathrm{fg}}$, which is positive for a positive slope of the saturated vapor line on the pressure-enthalpy diagram. Since this is the case in the temperature application range of a vapor compression cycle (far from the critical temperature), we may deduce that $\Delta \mathrm{Q}_{\mathrm{ECO}}$ is positive as well. The positive value of $\Delta \mathrm{Q}_{\mathrm{ECO}}$ and negative value of $\Delta \mathrm{W}_{\mathrm{ECO}}$ renders $\mathrm{COP}_{\mathrm{ECO}}$ greater than $\mathrm{COP}_{\mathrm{R}}$ for any fluid.

The results discussed in this section were generated by simulating the economizer cycle depicted in Figure 15. The evaporator and condenser reduced temperatures were 0.65 and 0.82 , respectively. Zero subcooling was used at the inlet to both expansion devices, and an adiabatic throttling process was assumed. The saturated vapor entering the compressor at $P_{\text {evap }}$ was compressed to the intermediate pressure, $P_{\text {int }}$. At the intermediate pressure, the saturated vapor from liquid-vapor separator (state 9) was mixed with the refrigerant that was compressed from the evaporator pressure (state 2). The saturation temperature of the intermediate pressure level was optimized for each refrigerant to obtain maximum COP.

The economizer cycle improves the COP for each fluid, but the extent of COP improvement depends on molar heat capacity, as shown in the next two figures. Figure 16 presents the capacity and work of the economizer cycle referenced to the respective values of the Rankine cycle. The capacity ratio and work ratio are well correlated by the molar heat capacity of vapor. As we have deduced earlier, changes in both capacity and work promote an improvement of the system $\mathrm{COP}_{\mathrm{ECO}}$.

The ratios of $\mathrm{COP}_{\mathrm{ECO}}$ and $\mathrm{COP}_{\mathrm{R}}$ to $\mathrm{COP}_{\mathrm{C}}$ for the studied fluids are presented in Figure 17. The figure shows that the economizer cycle improves the COP for every fluid, but the degree of COP improvement is larger for fluids with large heat capacity. The COPs of different refrigerants are more uniform for the economizer cycle than for the Rankine cycle. We may also notice that the best-performing fluids in the Rankine cycle are still the best performers in the economizer cycle.

The optimum intermediate saturation temperature, $\mathrm{T}_{\mathrm{int}}$, is fairly uniform for the fluids considered and can be well approximated by the mean temperature between the condenser and evaporator (i.e., $0.5\left(\mathrm{~T}_{\text {cond }}+\mathrm{T}_{\text {evap }}\right)$ ). There is some dependency of the optimum $\mathrm{T}_{\text {int }}$ on molar heat capacity, but it is rather small, as shown in Figure 18. The optimum pressure is also uniform, but correlates with more scatter. The geometric mean pressure (i.e., $\left.\left(\mathrm{P}_{\text {cond }} \cdot \mathrm{P}_{\text {evap }}\right)^{0.5}\right)$, which ensures the minimum work for two-stage compression of a perfect gas with complete intercooling [6], underestimates the optimum pressure for the real gases in the economizer cycle. The mean temperature also indicates the optimum intermediate temperature well for other combinations of evaporator and condenser temperatures.

Figure 19 shows the sensitivity of $\mathrm{COP}_{\mathrm{ECO}}$ on the selection of $\mathrm{T}_{\mathrm{int}}$ for four refrigerants of different molar heat capacity. As expected, selection of an appropriate $T_{\text {int }}$ was more critical for a fluid benefiting most from the economizer. In this case, R-227ea was most affected by 


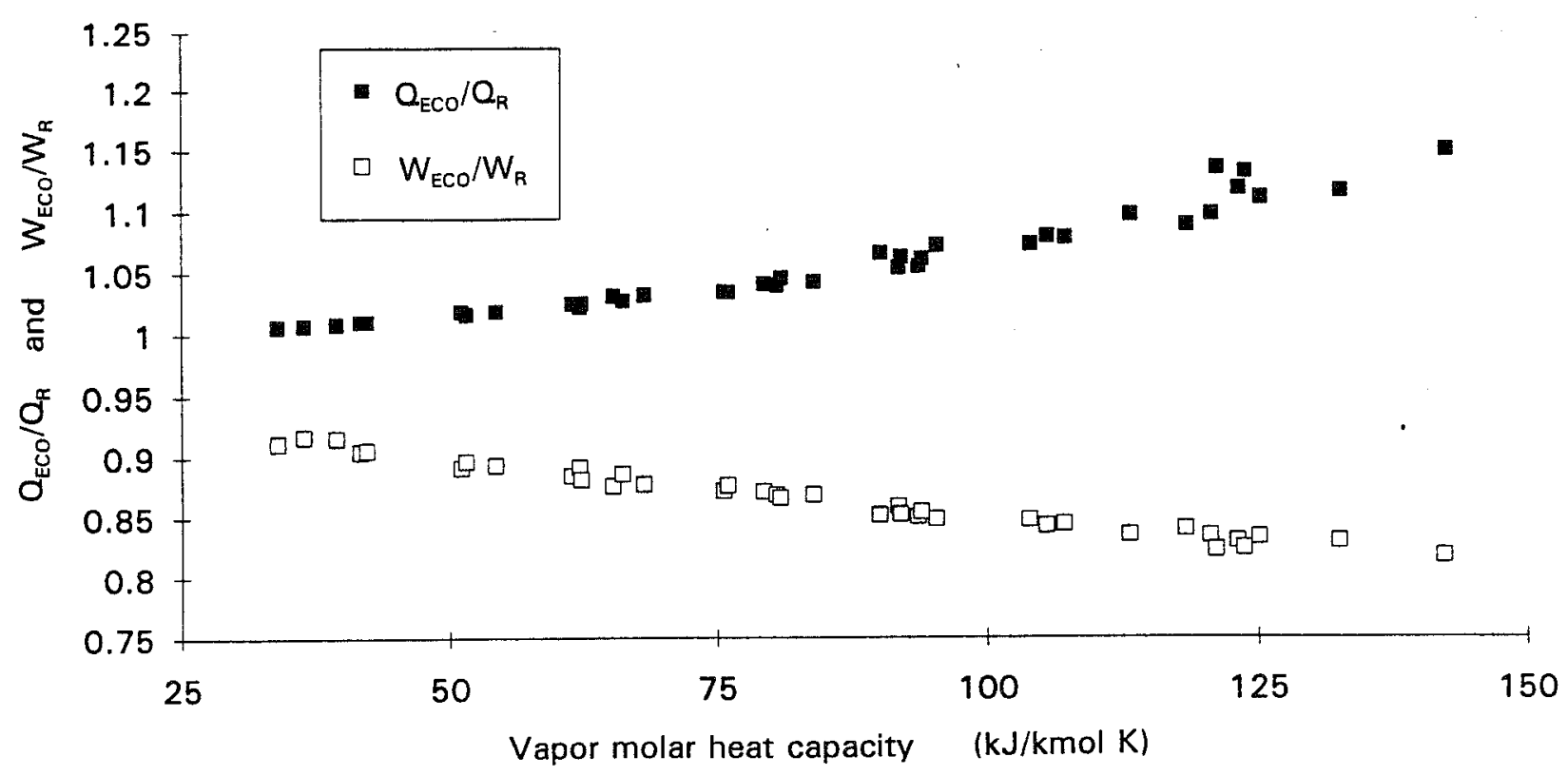

Figure 16. Capacity and work of the economizer cycle referenced to the capacity and work of the Rankine cycle $\left(\mathrm{T}_{\text {evap }, \mathrm{r}}=0.65, \mathrm{~T}_{\text {cond,r }}=0.82\right)$

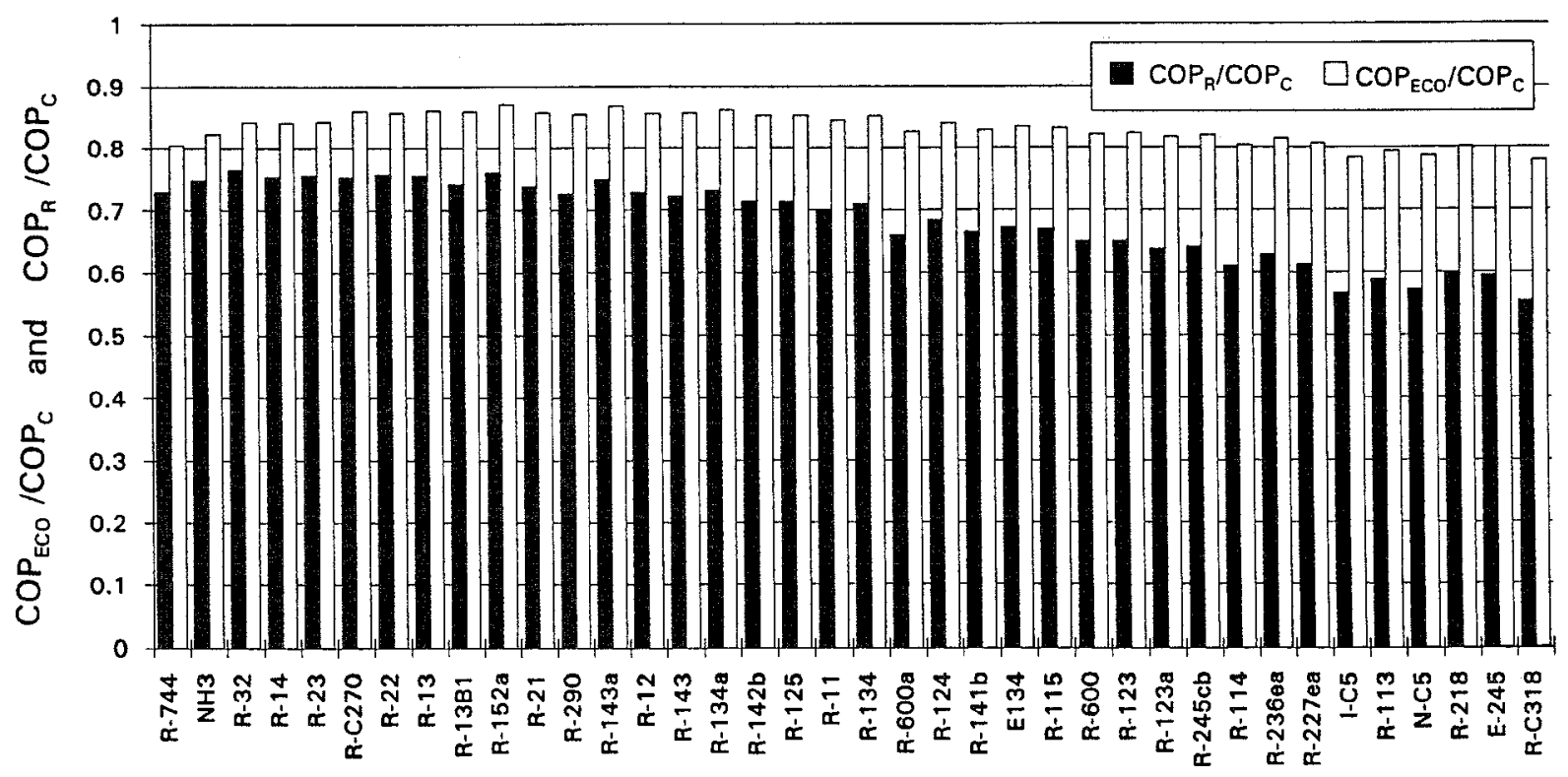

Figure 17. $\mathrm{COP}$ of the economizer and Rankine cycle referenced to $\mathrm{COP}_{\mathrm{C}} \quad\left(\mathrm{T}_{\text {evap }, \mathrm{r}}=0.65\right.$, $\mathrm{T}_{\text {cond, } \mathrm{r}}=0.82$, refrigerants sorted by $\mathrm{c}_{\mathrm{p}, \mathrm{v}}$ at $\mathrm{T}_{\text {evap }, \mathrm{r}}$ ) 


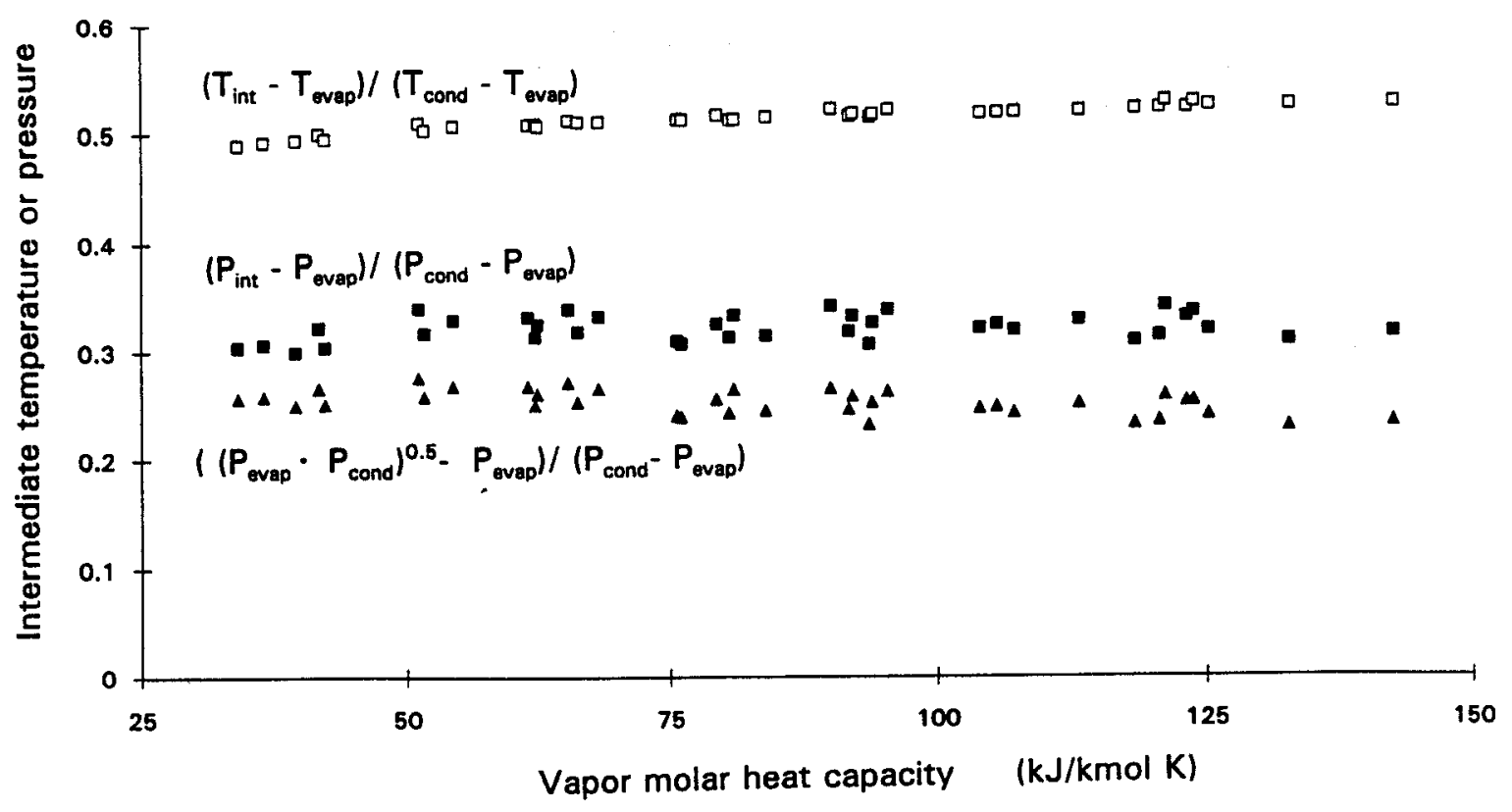

Figure 18. Optimum intermediate temperature, pressure, and geometric-mean intermediate pressure $\left(\mathrm{T}_{\text {evap }, \mathrm{r}}=0.65, \mathrm{~T}_{\text {cond, } \mathrm{r}}=0.82\right)$

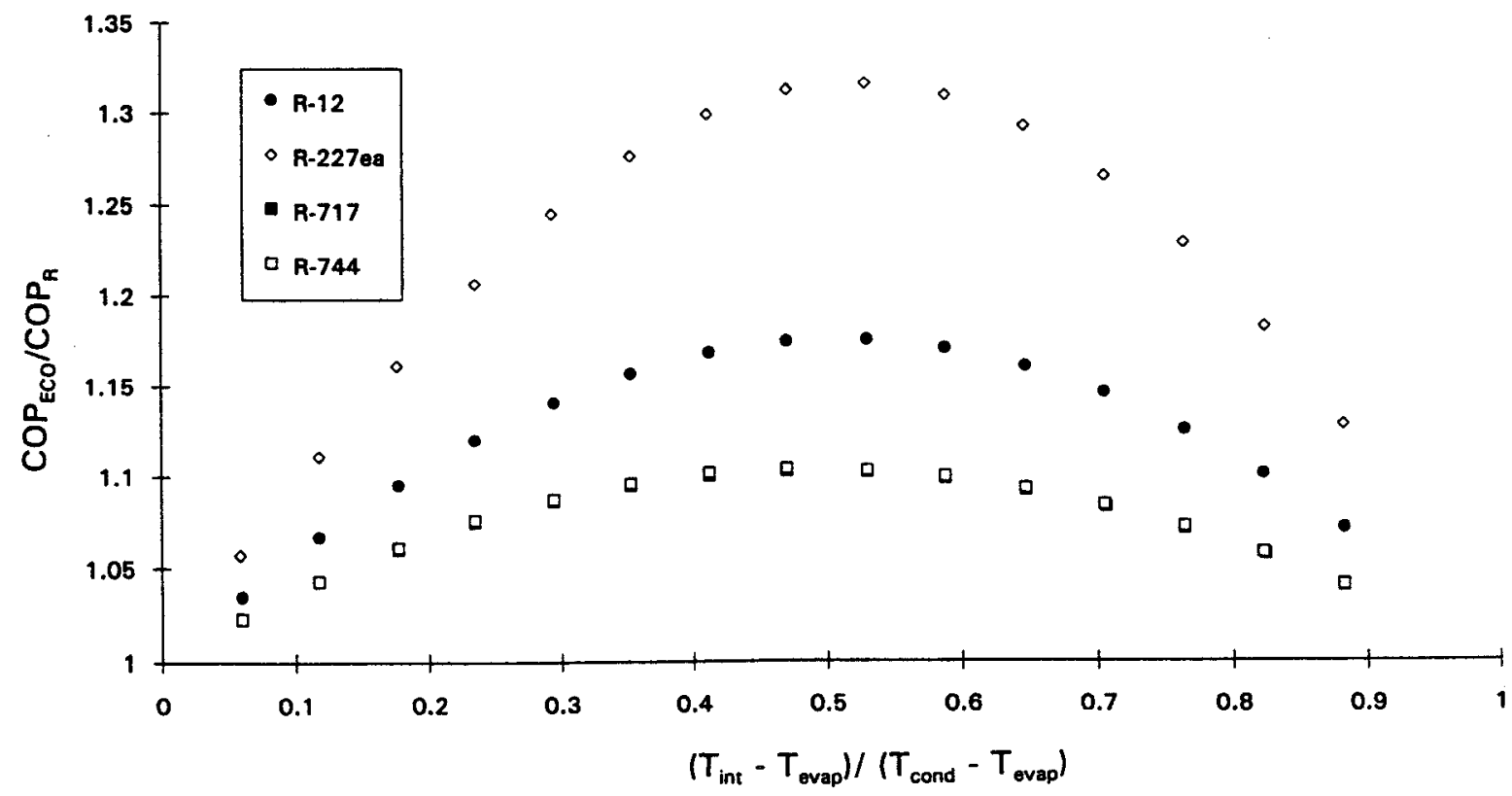

Figure 19. $\mathrm{COP}_{\mathrm{ECO}}$ as a function of the intermediate temperature for $\mathrm{R}-12, \mathrm{R}-227 \mathrm{ea}$, $\mathrm{R}-717$, and R-744 ( $\left.\mathrm{T}_{\text {evap }, \mathrm{r}}=0.65, \mathrm{~T}_{\text {cond }, \mathrm{r}}=0.82\right)$ 
the selection of $\mathrm{T}_{\text {int }}$. The potential improvement in the economizer cycle is related to the expansion losses for a given refrigerant. For example, ammonia and $\mathrm{CO}_{2}$ have similar molar heat capacity and expansion losses, and their points coincide in Figure 19 regardless of their quite different temperature lifts (resulting from different $T_{\text {crit }}$ ).

Additional simulations were performed for the specified absolute temperatures in the evaporator and condenser of $\mathrm{T}_{\text {evap }}=8^{\circ} \mathrm{C}$ and $\mathrm{T}_{\text {cond }}=46^{\circ} \mathrm{C}$. The COP results are presented in Figure 20. The relative trends in results are consistent with those for the same reduced temperatures discussed earlier in this section.

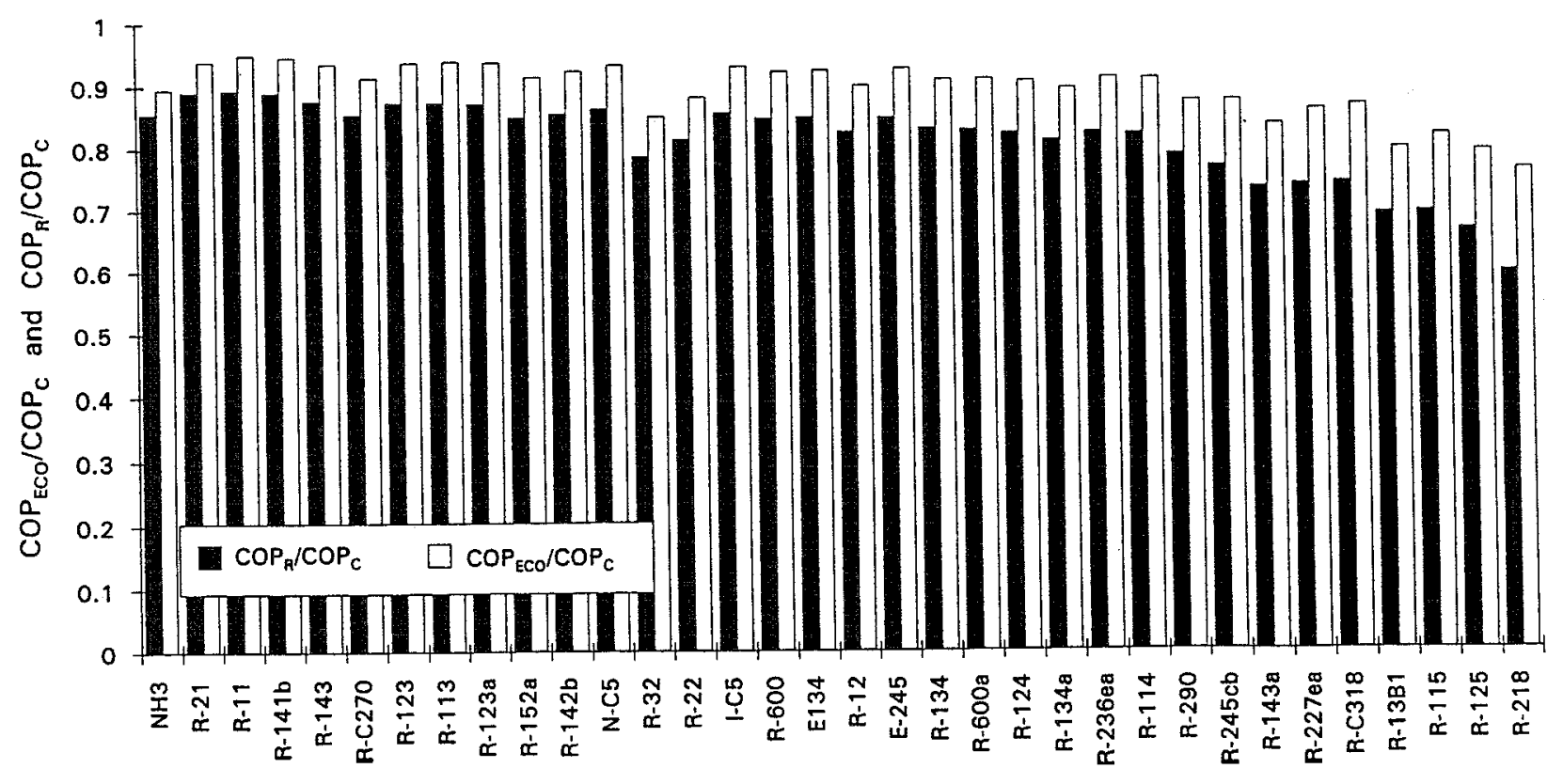

Figure 20. $\mathrm{COP}$ of the economizer cycle and Rankine cycle referenced to $\mathrm{COP}_{\mathrm{C}}$ $\left(\mathrm{T}_{\text {evap }}=8^{\circ} \mathrm{C} \quad \mathrm{T}_{\text {cond }}=46^{\circ} \mathrm{C}\right.$, refrigerant sorted by $\left.\bar{c}_{\mathrm{p}, \mathrm{I}} \mathrm{T}_{\text {evap }} / \mathrm{h}_{\mathrm{fg}}\right)$ 


\section{Ejector Cycle}

The majority of work on ejectors has been for single-phase applications. An extensive list of publications on the topic is given in [7]. In the application considered here, the ejector is employed to reduce throttling irreversibilities through the use of kinetic energy of flash gas to increase refrigerant suction pressure at the compressor inlet. Besides basic system components, the cycle includes a jet ejector and separator, which are configured in the system as shown in Figure 21. The ejector itself consists of four main parts: the motive (primary) nozzle, suction nozzle, mixing section, and diffuser. High-pressure refrigerant expands and accelerates in the motive nozzle and mixes with the refrigerant vapor which enters the ejector through the suction nozzle. The mixture decelerates in the diffuser which increases mixture pressure above the pressure in the evaporator. The separator separates the two-phase stream into saturated vapor and liquid. The vapor enters the compressor while the liquid is directed to the evaporator through a small-pressure-drop expansion device. Since the compression process starts from a higher pressure than the evaporator pressure, compression work is reduced. Also, withdrawal of energy from the expanding refrigerant results in a lower refrigerant quality entering the evaporator. The resulting effect is an increase in the cycle COP and volumetric capacity.

Simulating the ejector cycle involved many assumptions. As in the previous sections, the heat exchangers and connecting pipes were considered to have negligible pressure drop. Refrigerant leaving the evaporator and condenser was a saturated vapor and liquid, respectively. Isenthalpic expansion and isentropic compression were assumed. In calculations, the separator offered zero pressure drop and had 100\% effectiveness in separating the two-phase mixture into saturated vapor and liquid.

The analysis followed the assumptions and calculating scheme presented by Kornhauser [8] for one-dimensional simulation of the ejector. Properties and velocities of the refrigerant were assumed to be uniform over any cross section. The streams entering and leaving the ejector were at stagnation conditions, and the mixing of the motive fluid and secondary vapor took place at constant pressure. The processes in the motive and suction nozzles were represented by their respective efficiencies, so that velocities at the outlets could be calculated as follows:

The motive nozzle: $u_{m}=\sqrt{2\left(h_{m, i}-h_{m, o}\right)} \quad h_{m, o}=h_{m, i}-\eta_{m}\left(h_{m, i}-h_{m, o, i s}\right)$

The suction nozzle: $u_{s}=\sqrt{2\left(h_{s, i}-h_{s, 0}\right)} \quad h_{s, o}=h_{s, i}-\eta_{s}\left(h_{s, i}-h_{s, 0, i s}\right)$

where the enthalpies following the isentropic expansion, $h_{m, o \text {,is }}$ and $h_{s, 0, \text { is }}$, were defined by the respective inlet entropies to the nozzles and pressure in the mixing section. 

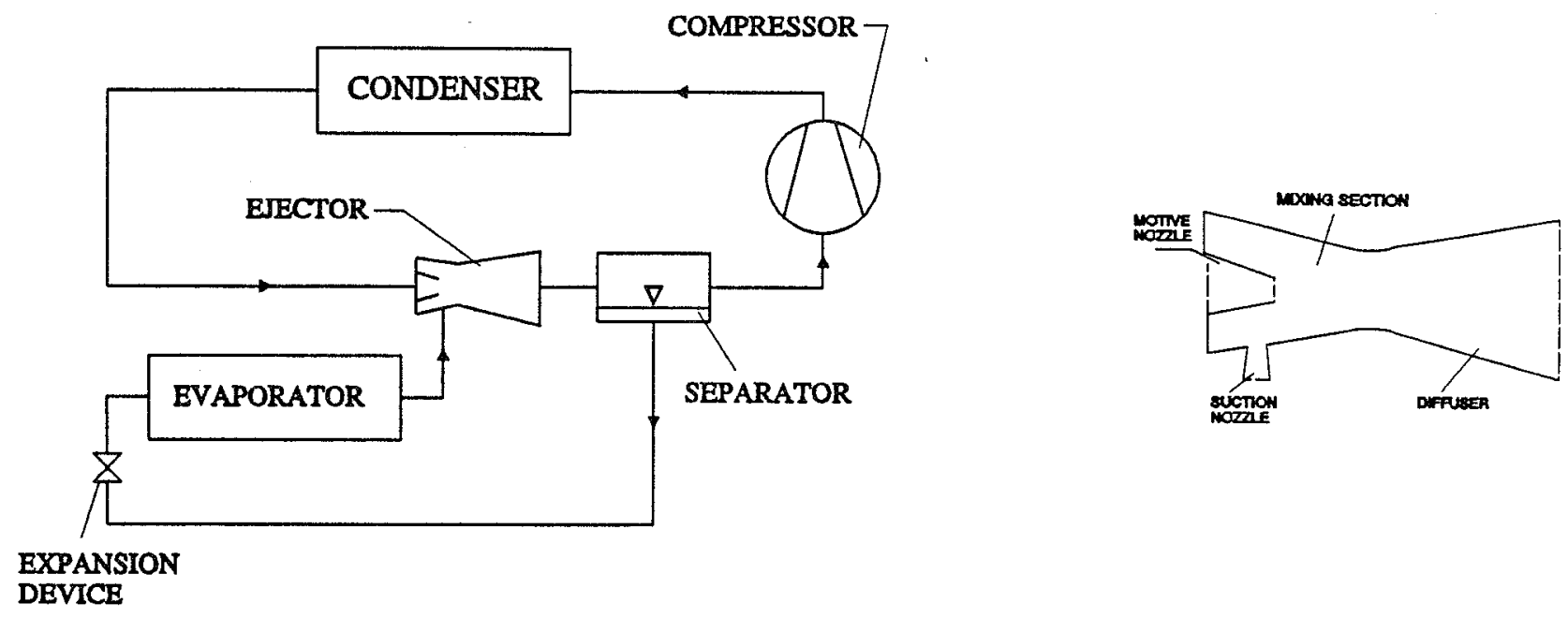

Figure 21. Schematic of the ejector system and ejector

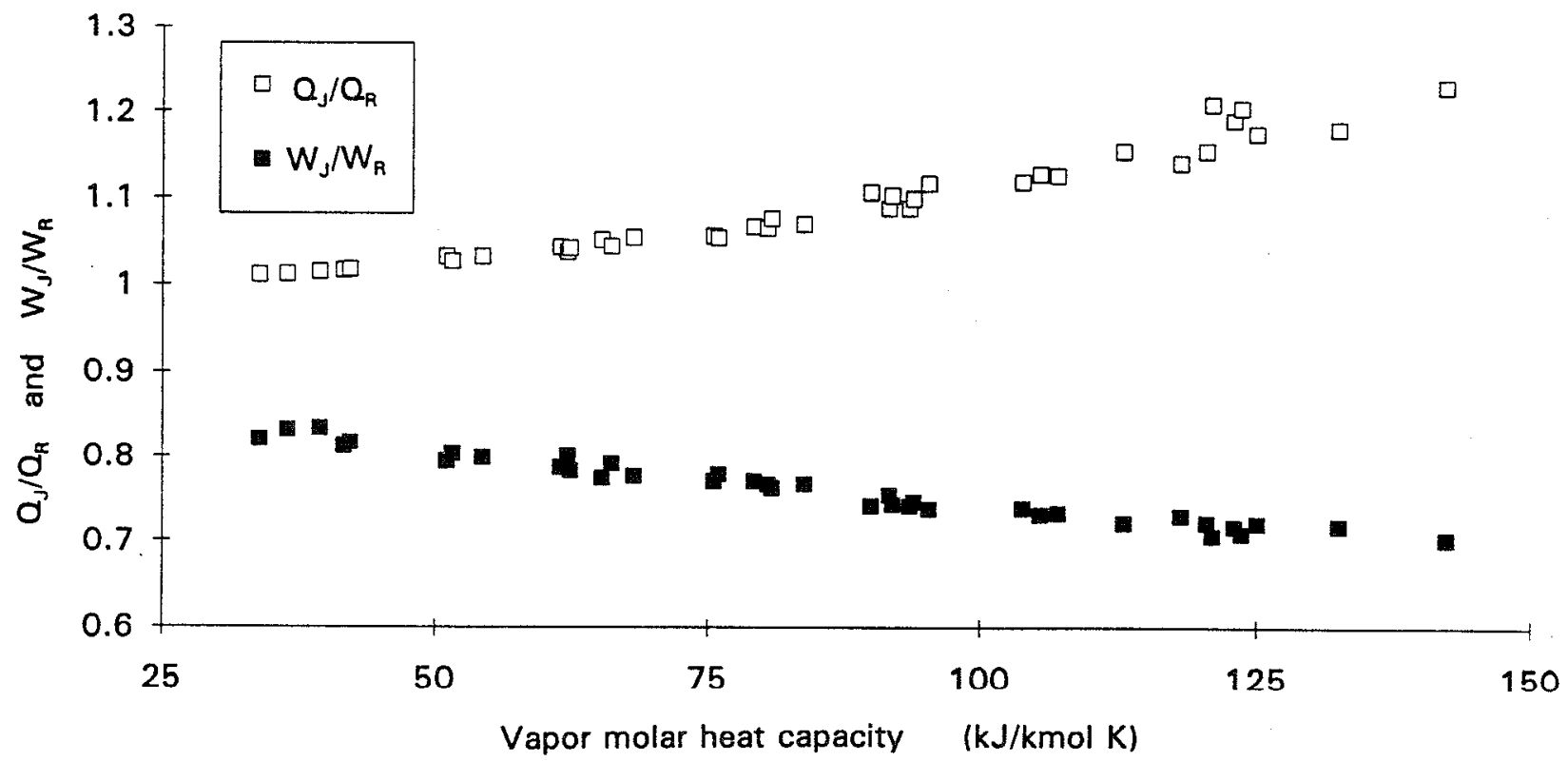

Figure 22. Capacity and work for the ejector cycle referenced to capacity and work for the Rankine cycle $\left(\mathrm{T}_{\text {evap }, \mathrm{r}}=0.65, \mathrm{~T}_{\text {cond }, \mathrm{r}}=0.82\right.$, ejector components $100 \%$ efficient $)$ 
Conservation of mass, momentum, and energy for the mixing process results in:

$$
\begin{aligned}
& r_{m}+r_{s}=1 \\
& u_{x}=u_{m} r_{m}+u_{s} r_{s} \\
& h_{x}=h_{m, i} \cdot r_{m}+h_{s, i} \cdot r_{s}-\frac{u_{x}^{2}}{2}
\end{aligned}
$$

Refrigerant enthalpy at the diffuser outlet was calculated by the equation:

$$
h_{d}=h_{x}+\frac{u_{x}^{2}}{2}
$$

The pressure at the diffuser outlet, $P_{d}$, was calculated applying the diffuser efficiency concept and the energy conservation equation:

$$
\begin{aligned}
& \mathrm{h}_{\mathrm{d}}^{\prime}=\mathrm{h}_{\mathrm{m}}+\eta_{\mathrm{d}} \frac{\mathrm{u}_{\mathrm{m}}^{2}}{2} \\
& \mathrm{P}_{\mathrm{d}}=\mathrm{f}\left(\mathrm{h}_{\mathrm{d}}, \mathrm{s}_{\mathrm{x}}\right)
\end{aligned}
$$

where $s_{x}$ is refrigerant entropy after the mixing process defined by $h_{x}$ and $P_{x}$.

The mixing pressure in the ejector affects the cycle performance. In all simulations performed for this study, the mixing pressure was optimized for each fluid to provide maximum COP. The cycle COP is also affected by the individual efficiencies of the motive nozzle, suction nozzle, and diffuser. The COP displays a different sensitivity to each component efficiency [7]. Different ejector component efficiencies were used in simulations, but they were all assigned the same efficiency level for a given simulation run. Therefore, the sensitivity of the COP to individual ejector components was not considered in this study.

As in the previous sections on llsl-hx and economizer, 38 refrigerants were simulated at reduced temperatures in the evaporator and condenser of 0.65 and 0.82 , respectively. As shown in Figure 22, the ejector cycle realizes an improvement in both the work requirement and capacity. On a percentage basis, the reduction in work is greater. For the same reduced temperatures in the evaporator and condenser, the extent of the benefit from the ejector cycle is well correlated by the molar heat capacity of vapor leaving the evaporator. The trend of $\mathrm{Q}_{\mathrm{j}} / \mathrm{Q}_{\mathrm{r}}$ and $\mathrm{W}_{\mathrm{j}} / \mathrm{W}_{\mathrm{r}}$ is very similar to that for the economizer cycle depicted in Figure 16 , but the benefit displayed in Figure 22 (which presents the results for all ejector component efficiencies equal to $100 \%$ ) is greater. However, when the ejector component efficiencies are all lowered to $80 \%$, the results are nearly identical to the economizer cycle. 
Figure 23 presents the COP of the ejector cycle for different levels of ejector component efficiency. The lowest bars in the figure are for a system with the ejector efficiency equal to zero, which reduces the ejector cycle to the Rankine cycle. The additional bar fragments indicate COPs for different levels of ejector component efficiency. In general, the ejector cycle COP is very sensitive to the ejector efficiency. This sensitivity increases at the higher end of ejector component efficiency. In other words, for the same increment in efficiency the COP improvement is larger at a larger component efficiency value. At low ejector component efficiencies, low-heat-capacity refrigerants have a better COP. At high ejector component efficiencies, high-heat-capacity fluids show a higher COP, but it is uncertain whether such high efficiency levels can be attained in two-phase ejectors.

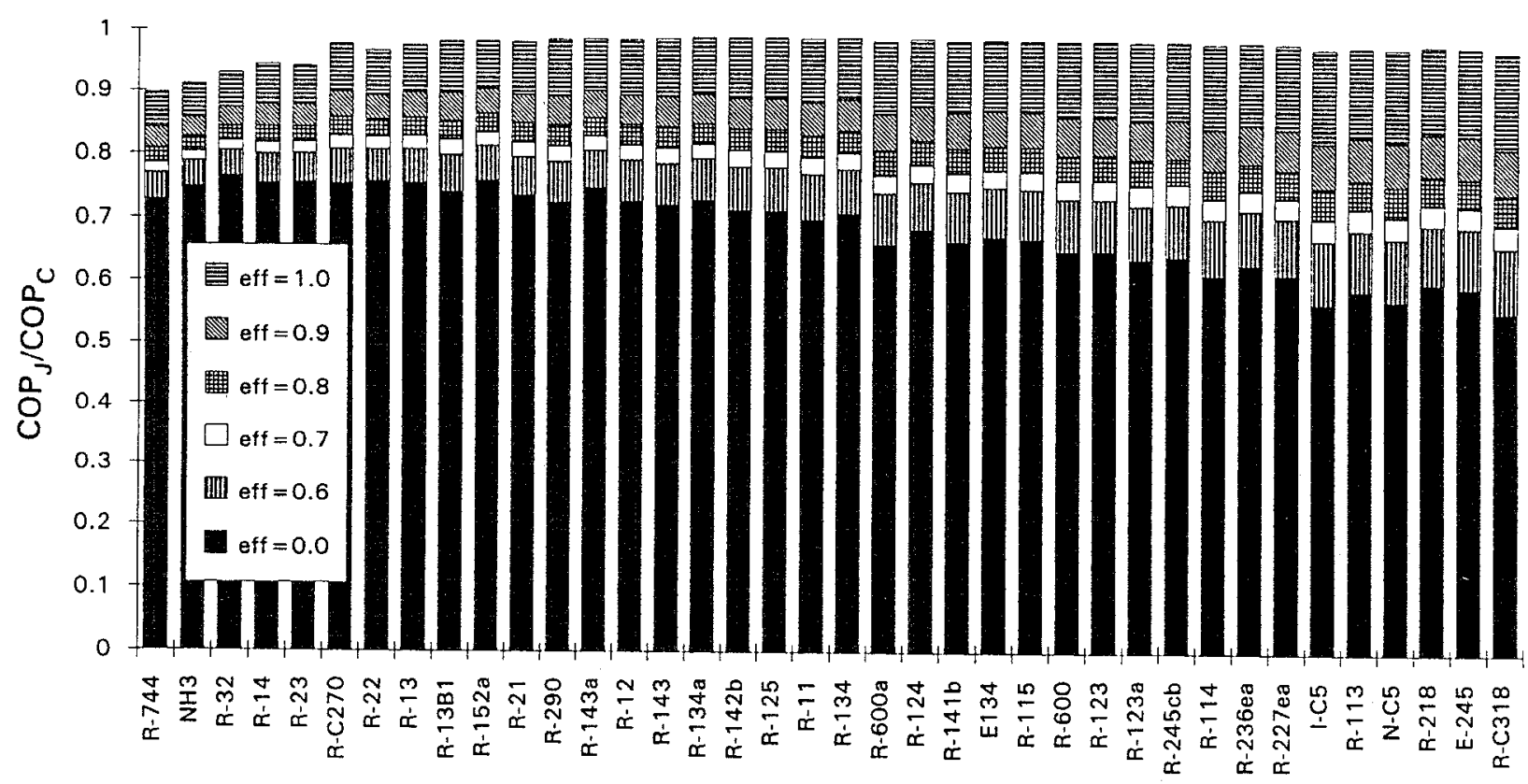

Figure 23. COP of the ejector cycle referenced to $\operatorname{COP}_{C} \quad\left(T_{\text {evap }, \mathrm{r}}=0.65, T_{\text {cond, }}=0.82\right.$, refrigerants sorted by $c_{p, v}$ at $T_{\text {evap,r }}$ ) 
Figure 24 supplements the information of Figure 23 by presenting the COP percent improvement over the $\mathrm{COP}_{R}$. The figure shows an improvement (referenced to $\mathrm{COP}_{R}$ ) for a given ejector component-efficiency level. The bottom bar indicates the improvement over the Rankine cycle for the ejector component efficiency equal to 0.6. Each additional bar denotes an additional COP improvement over the lower-efficiency level of ejector components.

Figures 25,26 , and 27 present simulation results for selected refrigerants at assigned absolute temperatures in the evaporator and condenser, $\mathrm{T}_{\text {evap }}=8^{\circ} \mathrm{C}, \mathrm{T}_{\text {cond }}=46^{\circ} \mathrm{C}$. In addition to a COP improvement, Figure 27 shows that the ejector cycle also improves the volumetric capacity. For most of the fluids the improvement in the volumetric capacity is larger than the COP increase.

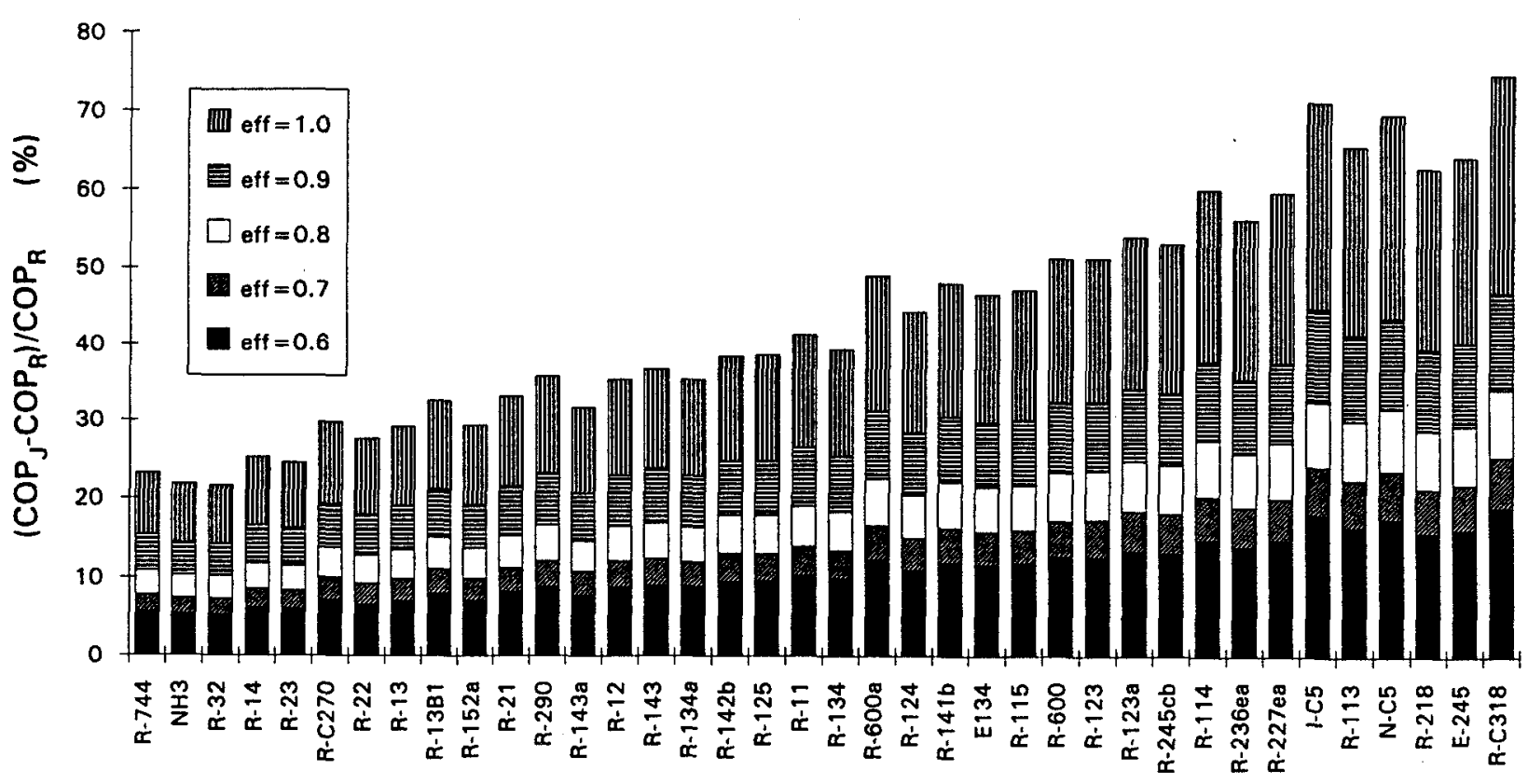

Figure 24. COP improvement of the ejector cycle over the $\operatorname{COP}_{\mathrm{R}}\left(\mathrm{T}_{\text {evap }, \mathrm{r}}=0.65, \mathrm{~T}_{\text {cond }, \mathrm{r}}=0.82\right.$, refrigerants sorted by $c_{p, v}$ at $T_{\text {evap,r }}$ ) 


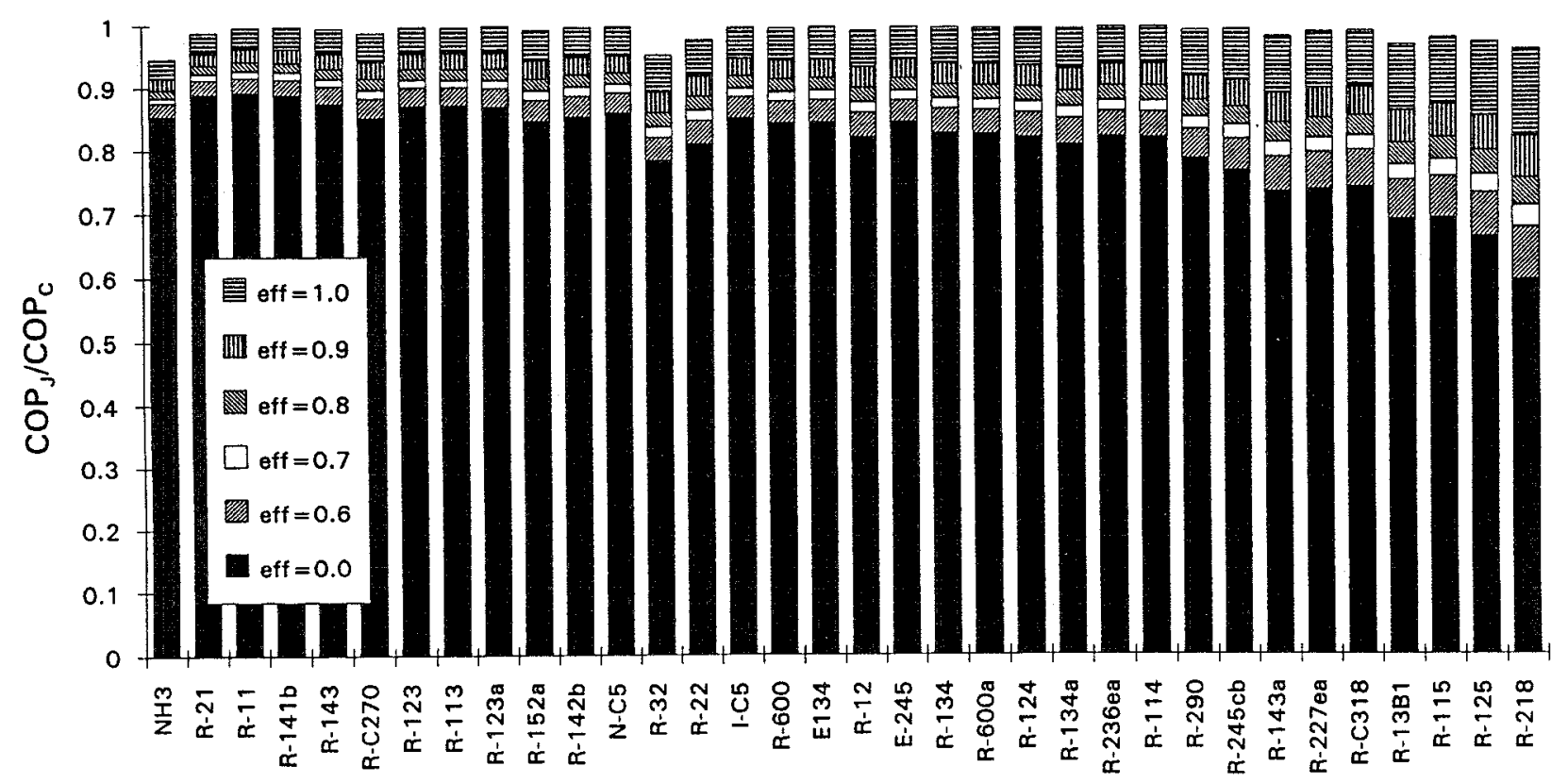

Figure 25. COP of the ejector cycle referenced to $\mathrm{COP}_{\mathrm{C}}\left(\mathrm{T}_{\text {evap }}=8^{\circ} \mathrm{C}, \mathrm{T}_{\text {cond }}=46^{\circ} \mathrm{C}\right.$, refrigerants sorted by $\bar{c}_{\mathrm{p}, \mathrm{l}} \mathrm{T}_{\mathrm{evap}} / \mathrm{h}_{\mathrm{fg}}$ )

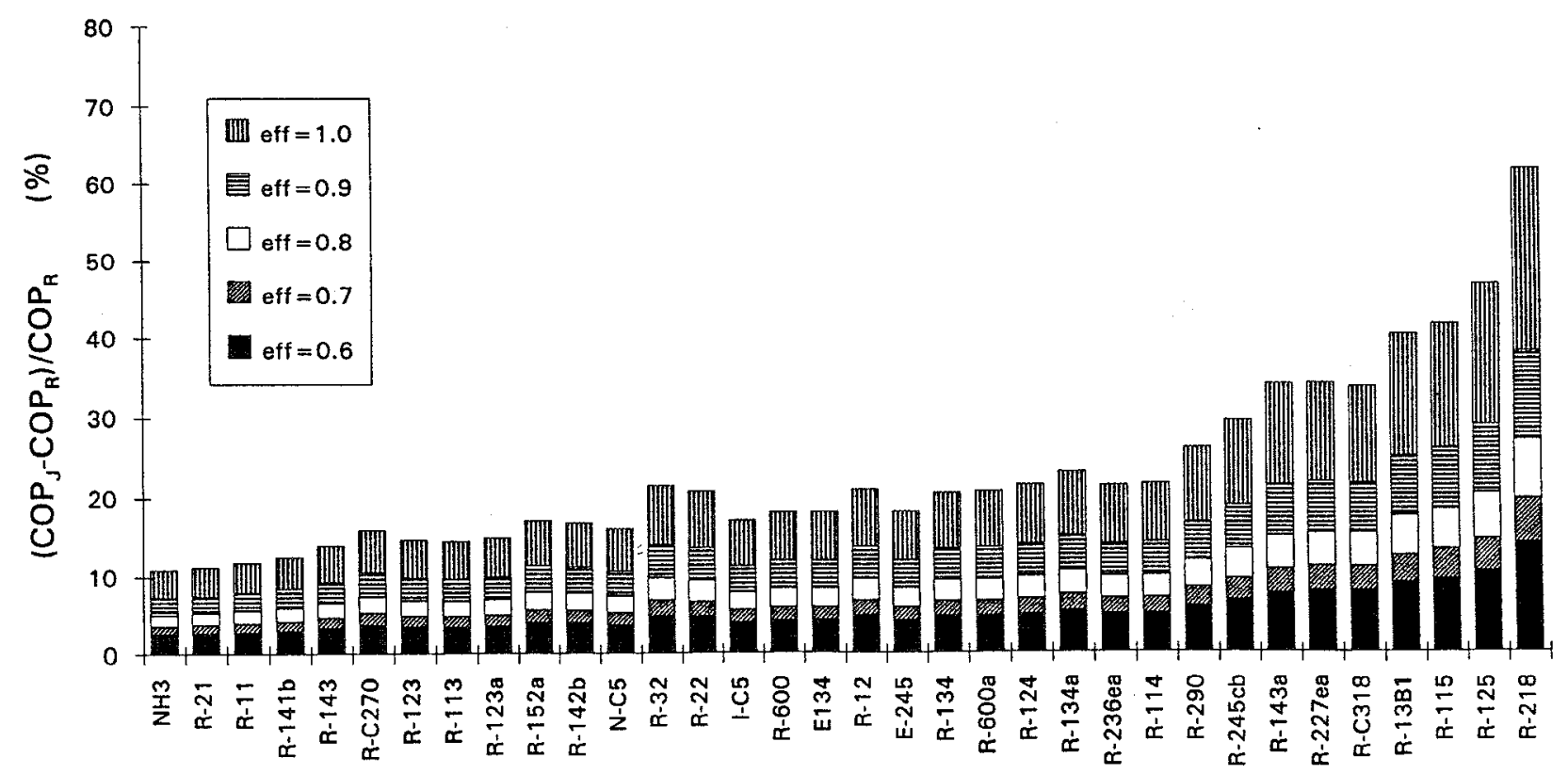

Figure 26. COP improvement of the ejector cycle over the $\operatorname{COP}_{\mathrm{R}}\left(\mathrm{T}_{\text {evap }}=8^{\circ} \mathrm{C}\right.$, $\mathrm{T}_{\text {cond }}=46^{\circ} \mathrm{C}$, refrigerants sorted by $\bar{c}_{\mathrm{p}, 1} \mathrm{~T}_{\text {evap }} / \mathrm{h}_{\mathrm{fg}}$ ) 


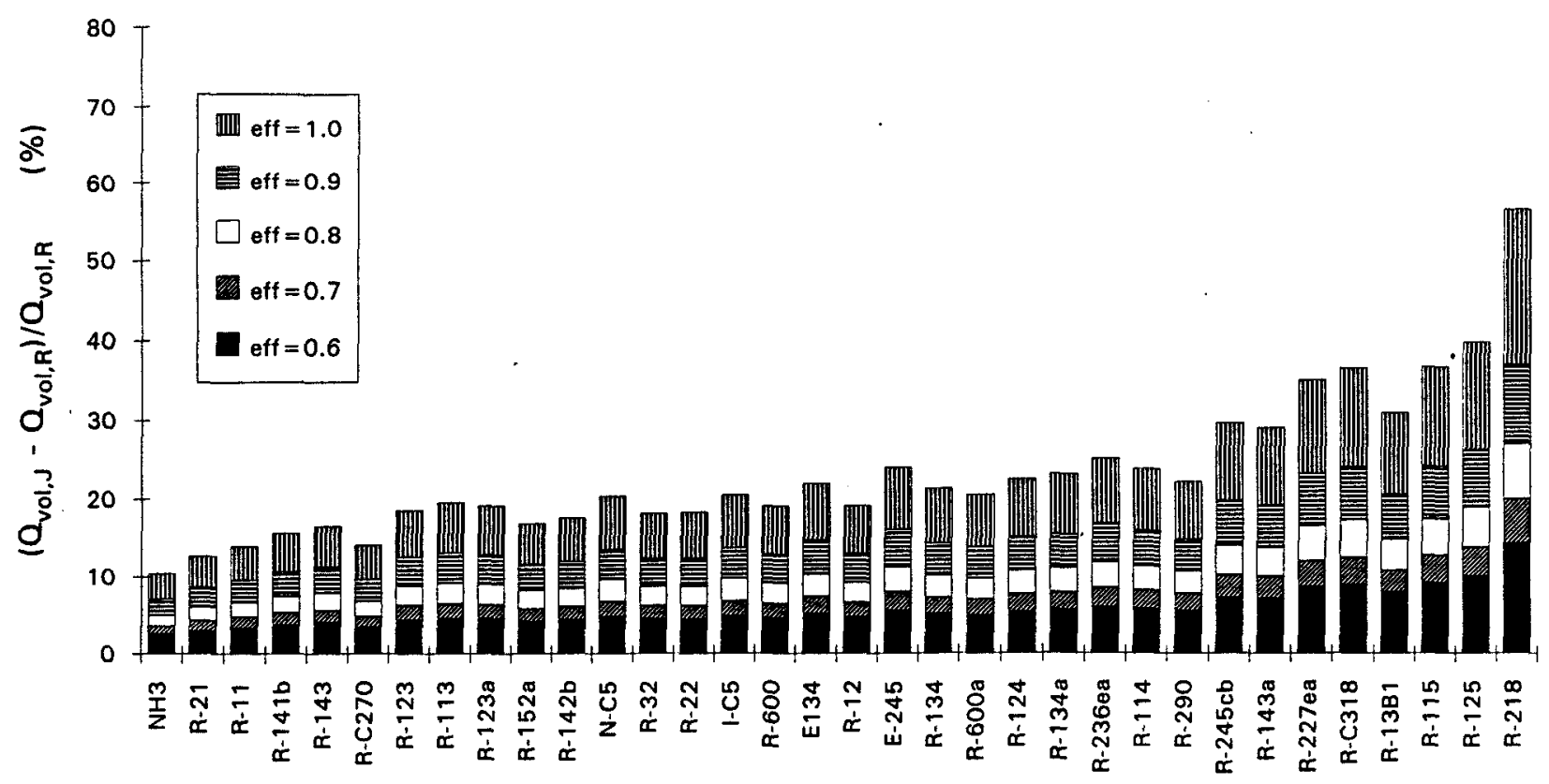

Figure 27. Improvement of volumetric capacity of the ejector cycle over that of the Rankine cycle $\left(\mathrm{T}_{\text {evap }}=8^{\circ} \mathrm{C}, \mathrm{T}_{\text {cond }}=46^{\circ} \mathrm{C}\right.$, refrigerants sorted by $\left.\bar{c}_{\mathrm{p}, 1} \mathrm{~T}_{\text {evap }} / \mathrm{h}_{\mathrm{fg}}\right)$

\section{Summary}

The objective of this study was to compare the theoretical COP potential of three alternatives to the Rankine cycle: the liquid-line/suction-line heat exchange cycle, economizer cycle, and ejector cycle. All three modified cycles reduce throttling irreversibilities which vary with evaporator and condenser temperature and from one refrigerant to another.

To limit the infinite possibilities for operating conditions that could be used in this study, simulations were performed at one set of reduced temperatures and one set of absolute temperatures in the evaporator and condenser. The reduced temperature approach evaluates fluids at different temperature lifts and allows screening of all fluids. The absolute temperature evaluation is more oriented towards a given application. General observations from both simulations are summarized below.

The cycle with liquid-line/suction-line heat exchange showed the smallest COP improvement potential of the three cases studied. In fact, its incorporation into the cycle penalizes the COP of refrigerants with small molar heat capacity, which are the highest $\mathrm{COP}_{R}$ fluids in the reduced temperature screening. The llsl-hx improves the COP of large molar heat capacity refrigerants which have a low $\operatorname{COP}_{\mathrm{R}}$. At the theoretical limit of 100 percent llsl-hx 
effectiveness, these fluids can achieve the highest COP of all refrigerants. At smaller, realistic values of llsl-hx effectiveness, the COP of all refrigerants is approximately even. The COP change approximates the change in volumetric capacity effected by the llsl-hx [5].

Incorporation of the llsl-hx results in additional superheat at the compressor inlet and increased temperature at the compressor discharge. This aspect may preclude the use of llsl$\mathrm{hx}$ with small and moderate heat capacity fluids; however, it may encourage the use with large heat capacity refrigerants for which the compression process results in a two-phase discharge condition when no superheat exists at the compressor inlet.

Although the llsl-hx may be the easiest to implement on the a unitary product, the economizer cycle is the easiest to implement on a large chiller with either multistage centrifugal or screw compressors. In some systems, the llsl-hx may be implemented by providing a physical contact between the existing suction and liquid lines. If a special heat exchanger has to be installed to facilitate the heat exchange, its pressure drop on the vapor side will diminish or may even eliminate the COP benefit of this heat exchanger.

The economizer cycle is a more complicated option, but it improves the COP for all fluids. The improvement results from both the increased capacity and reduced work, the latter having a more significant effect. The fluids performing worst in the Rankine cycle benefited most in the economizer cycle. Similar to the llsl-hx cycle, the economizer tends to even performance for all refrigerants but at a higher level; the $\mathrm{COP}_{\mathrm{ECO}}$ is approximately 10 to 15 percent greater than $\mathrm{COP}_{\mathrm{hx}}$ for individual fluids. Still better $\mathrm{COP}_{\mathrm{ECO}}$ could be attained in a two-stage economizer cycle. Compared to a single stage, the second stage does not provide as large an incremental improvement although it can still be significant; an additional 5\% COP improvement on the top of $16 \%$ single-stage improvement was evaluated in [9] for R-22 at $\mathrm{T}_{\text {cond }}=40^{\circ} \mathrm{C}$ and a condenser/evaporator pressure ratio of 12 .

The economizer cycle requires a special compressor with an economizer inlet port. In practice, this modification is applied to centrifugal and screw compressors, and may not be possible for other types of compressors. Thus, the economizer concept may not be applicable to all refrigeration applications unless staged compressors are employed.

Similar to the economizer cycle, the ejector cycle improves the COP for all refrigerants. The improvement comes from both increased capacity and reduced compression work. The COP improvement is sensitive to the ejector's efficiency. This dependence increases strongly with the efficiency of the ejector (i.e., the same incremental increase in ejector efficiency provides a larger improvement of system COP at a higher ejector-efficiency level).

With the assumptions used in this study, the ejector cycle has a better COP than the onestage economizer cycle if the efficiency of ejector components (primary nozzle, secondary nozzle, and diffuser) is better than 80 percent. It is unclear whether this high level of component efficiency can be achieved in a two-phase ejector. It is probably safe to assume that the efficiencies attainable in a single-phase system $(0.85-0.9$ for a nozzle and 0.7 for a 
diffuser) are the practical limit for two-phase ejectors. With very little research done so far on two-phase ejectors, it is unknown to what degree they can approach the performance of the single-phase devices. When the single-phase component efficiencies $(0.85$ for a nozzle and 0.7 for a diffuser) were applied in simulations for R-134a at two operating conditions $\left(T_{\text {evap }}=-10^{\circ} \mathrm{C}, T_{\text {cond }}=46^{\circ} \mathrm{C}\right.$, and $T_{\text {evap }}=8^{\circ} \mathrm{C}, \mathrm{T}_{\text {cond }}=46^{\circ} \mathrm{C}$ ), the economizer cycle had a marginally better $\mathrm{COP}$ than the ejector cycle.

The application of the ejector is not limited by the refrigeration system size or design, unless there is some limitation as to the size and capacity of the ejector itself. The ejector package can be incorporated into a system with typical components, although some component size change may be warranted to obtain the COP or economical optimum.

The similar feature for all three modified cycles is that their capability to improve the system COP increases with the amount of the throttling losses. For a given application $\left(T_{\text {evap }}\right.$ and $T_{\text {cond }}$ ) these losses are related to the ratio $\bar{c}_{\mathrm{p}, \mathrm{l}} / \mathrm{h}_{\mathrm{fg}}$; for a given fluid, the throttling losses increase with the temperature lift $\left(\mathrm{T}_{\text {cond }}-\mathrm{T}_{\text {evap }}\right)$.

The theoretical character of this study has to be emphasized. No refrigerant heat-transfer coefficients, transport properties, or system effects were considered. Several modeling simplifications and assumptions were accepted for simulations. Some of the assumptions were identical for all three cases (e.g., zero superheat at the evaporator outlet) while others were applied to a given system (e.g., no losses at the intermediate port of the compressor in the economizer cycle or no losses in the ejector cycle separator). Although these results have to be taken with some degree of caution, it is believed that they fairly assess the relative merits of the three cycles studied.

\section{References}

1. Gallagher, J., McLinden, M., Morrison, G., and Huber, M., "NIST Thermodynamic Properties of Refrigerants and Refrigerant Mixtures Database (REFPROP)", Version 4., NIST Standard Reference Database 23, National Institute of Standards and Technology, Gaithersburg, MD, November 1993.

2. Morrison, G., "Alternative Refrigerant Properties Measurement and Correlation Program at NIST", Proceedings of XI ${ }^{\text {th }}$ IUPAC Conference on Chemical Thermodynamics, Como, Italy, Pure and Applied Chemistry, Vol. 63, pp. 1465$1472,1991$.

3. Duffield, J.S., and Hodgett, D.L., "The Choice of Working Fluids for Heat Pumps Condensing at up to $120^{\circ} \mathrm{C}$ ", Proceedings of the $\mathrm{XV}^{\text {th }}$ Int. Congress of Refrigeration, Vol. II, pp. 259-265, Venice, 1979.

4. Reid, R.C., Prausnitz, J.M., and Poling, B.E., "The Properties of Gases and Liquids", McGraw-Hill, Inc., New York, NY, 1987. 
5. Domanski, P.A., Didion, D.A., and Doyle, J.P., "Evaluation of Suction-Line/Liquid -Line Heat Exchange in the Refrigeration Cycle", Int. J. Ref., Vol. 17, pp. 487-493, 1994.

6. Threlkeld, J.L., "Thermal Environmental Engineering", Prentice-Hall, Inc., Englewood Cliffs, NJ, 1970.

7. Huang, B.J., Jiang, C.B., and Hu, F.L., "Ejector Performance Characteristics and Design Analysis of Jet Refrigeration System", Transactions of ASME, Vol. 107, pp. 792-802, July 1985.

8. Kornhauser, A.A., "The Use of an Ejector as a Refrigerant Expander", Proc. ASHRAE-Purdue CFC Conference, Int. Inst. Refrig., Paris, pp. 10-19, 1990.

9. Jonsson, S., "Performance Simulations of Twin-Screw Compressors with Economizer", Int. J. Refrig., Vol. 14, pp. 345-350, November 1991. 